This document is confidential and is proprietary to the American Chemical Society and its authors. Do not copy or disclose without written permission. If you have received this item in error, notify the sender and delete all copies.

\title{
Novel scaffolds for Dual specificity tyrosine- phosphorylation-regulated kinase (DYRK1A) inhibitors
}

\begin{tabular}{|c|c|}
\hline Journal: & Journal of Medicinal Chemistry \\
\hline Manuscript ID & jm-2017-01847p.R3 \\
\hline Manuscript Type: & Article \\
\hline Date Submitted by the Author: & $n / a$ \\
\hline Complete List of Authors: & $\begin{array}{l}\text { Czarna, Anna; Faculty of Health Sciences, The Arctic University of Norway, } \\
\text { Department of Pharmacy } \\
\text { Wang, Jinhua; Dana-Farber Cancer Institute, Department of Cancer Biology } \\
\text { Zelencova, Diana; University of Tromsø, The Norwegian Structural Biology } \\
\text { Centre, Department of Chemistry } \\
\text { Liu, Yao; Dana-Farber Cancer Institute, Department of Cancer Biology } \\
\text { Deng, Xianming; Dana-Farber Cancer Institute, Department of Cancer } \\
\text { Biology } \\
\text { Choi, Hwan Geun; Dana-Farber Cancer Institute, Department of Cancer } \\
\text { Biology } \\
\text { Zhang, Ting-hu; Dana-Farber Cancer Institute, Department of Cancer } \\
\text { Biology } \\
\text { Zhou, Wenjun ; Dana-Farber Cancer Institute, Department of Cancer } \\
\text { Biology } \\
\text { Chang, Jae Won; Dana-Farber Cancer Institute, Department of Cancer } \\
\text { Biology } \\
\text { Kildalsen, Hanne; Faculty of Health Sciences, The Arctic University of } \\
\text { Norway, Department of Pharmacy } \\
\text { seternes, Ole-morten; Universitetet i Tromso Helsevitenskapelige fakultet } \\
\text { Helsefak, Pharmacy } \\
\text { Gray, Nathanael; Dana Farber Cancer Institute, Cancer Biology; Harvard } \\
\text { Medical School, Dana-Farber Cancer Institute } \\
\text { Engh, Richard; University of Tromsoe, Chemistry } \\
\text { Rothweiler, Ulli; University of Troms } \varnothing, \text { The Norwegian Structural Biology } \\
\text { Centre, Department of Chemistry }\end{array}$ \\
\hline
\end{tabular}




\title{
Novel scaffolds for Dual specificity tyrosine-
}

\section{phosphorylation-regulated kinase (DYRK1A) inhibitors}

\author{
Anna Czarna ${ }^{1}$, Jinhua Wang $^{2}$, Diana Zelencova ${ }^{3, \dagger}$, Yao Liu ${ }^{2}$, Xianming Deng ${ }^{2}$, Hwan Geun Choi ${ }^{2}$, \\ Tinghu Zhang ${ }^{2}$, Wenjun Zhou', Jae Won Chang ${ }^{2}$, Hanne Kildalsen ${ }^{1}$, Ole Morten Seternes ${ }^{1}$, \\ Nathanael S. Gray ${ }^{2}$, Richard A. Engh ${ }^{3}$ and Ulli Rothweiler ${ }^{3 *}$ \\ ${ }^{1}$ Department of Pharmacy, Faculty of Health Sciences, The Arctic University of Norway, \\ N-9037 Tromsø, Norway \\ ${ }^{2}$ Department of Cancer Biology, Dana-Farber Cancer Institute, Department of Biological \\ Chemistry and Molecular Pharmacology, Harvard Medical School, \\ Boston, MA 02115, USA \\ ${ }^{3}$ The Norwegian Structural Biology Centre, Department of Chemistry, UiT, The Arctic \\ University of Norway, N-9037 Tromsø, Norway \\ ${ }^{\dagger}$ Current address: Department of Physical Organic Chemistry, Latvian Institute of Organic \\ Synthesis, Aizkraukles 21, LV-1006, Riga, Latvia
}




\begin{abstract}
DYRK1A is one of five members of the Dual-specificity tyrosine (Y) phosphorylation-Regulated Kinase (DYRK) family. The DYRK1A gene is located in the Down syndrome critical region and regulates cellular processes related to proliferation and differentiation of neuronal progenitor cells during early development. This has focused research on to its role in neuronal degenerative diseases, including Alzheimer's and Down syndrome; recent studies have also shown a possible role of DYRK1A in diabetes. Here we report a variety of scaffolds not generally known for DYRK1A inhibition, demonstrating their effects in in vitro assays and also in cell cultures. These inhibitors effectively block the tau phosphorylation that is a hallmark of Alzheimer's Disease. The crystal structures of these inhibitors support the design of optimized and novel therapeutics.
\end{abstract}

\title{
INTRODUCTION
}

Alzheimer's disease (AD) is the primary cause of dementia in the elderly ${ }^{1}$. AD affects less than $5 \%$ of individuals 65 years of age and younger, but the incidence of $\mathrm{AD}$ reaches nearly $40 \%$ in patients 85 years of age and older ${ }^{1}$. This neurodegenerative disorder is characterized by neuronal death and loss of gray matter in the frontal cortex and hippocampus. This neurodegenerative disorder is characterized by neuronal death and loss of gray matter in the frontal cortex and hippocampus. Memory loss is a typical symptom of AD and has been linked to the accumulation of amyloid plaques and neurofibrillary tangles (NFTs) ${ }^{2}$. The latter process is mediated by hyperphosphorylation of tau proteins that are inactive and form multiple aggregates. According to the $\beta$-amyloid cascade hypothesis, the deposition of insoluble $\beta$-amyloid is responsible for neuronal death. Plaques are constituted by $\beta$-amyloid peptides $(\mathrm{A} \beta)$ that are generated via the cleavage of the amyloid precursor protein (APP) by $\beta$ - and $\gamma$-secretases. A $\beta$-fragments, $37-42$ 
amino acids in length, may produce soluble oligomers, although they aggregate into insoluble $\beta$-amyloid plaques in $\mathrm{AD}^{2,3}$. Alternatively, the insoluble hyperphosphorylated tau proteins and the buildup of NFTs may be the etiology of neuronal death ${ }^{4-6}$. Both mechanisms of neuronal pathology depend on the kinase DYRK1A, which regulates the cell cycle, neuronal differentiation and synaptic transmission ${ }^{7}$.

Increased levels of DYRK1A are present in the brain of patients with $\mathrm{AD}$ and in other neurodegenerative diseases, including Parkinson, Huntington and Pick syndromes ${ }^{7}$. The human DYRK1A gene is located in the Down syndrome critical region (DSCR) encoded by chromosome 21, and the overexpression of DYRK1A likely contributes to the neurological abnormalities of this disorder ${ }^{8}$.

DYRK1A increases the secretase-mediated cleavage of APP into A $\beta$ peptides. DYRK1A phosphorylates APP directly ${ }^{9}$ and the A $\beta$ peptides stimulate DYRK1A expression in a positive feedback loop ${ }^{9}$. Additionally DYRK1A phosphorylates presenilin 1 (PSEN1) ${ }^{10}$, one of the four core proteins in the $\gamma$-secretase complex, which enhances secretase activity. DYRK1A phosphorylates human microtubule associated protein tau at eleven different sites $^{11}$, whereby most of the tau protein becomes hyperphosphorylated. The initial phosphorylation of tau by DYRK1A triggers tau phosphorylation by GSK3 $\beta$, which potentiates self-aggregation and fibril formation in vitro ${ }^{11,12}$. Because of the central role of DYRK1A in the development and progression of $\mathrm{AD}$, DYRK1A has emerged as a high priority target for inhibition, offering a novel approach for the treatment of AD. In recent years, evidence has built up that point to a role of DYRK1A in diabetes and $\beta$-cell proliferation ${ }^{13-15}$, expanding the pharmaceutical application of a DYRK1A inhibitor. Therefore, we screened a diverse set of scaffolds for their ability to inhibit DYRK1A kinase activity and to prevent tau phosphorylation. The diversity of the novel scaffolds 
and the binding modes determined by crystal structure and in vitro assays may lead to the development of novel strategies for the clinical treatment of AD.

\section{RESULTS}

\section{Identification of novel DYRK1A inhibitors}

Novel DYRK1A inhibitors were identified by employing KinomeScan ${ }^{\mathrm{TM}}$ screening data of an in-house library of approximately 1,000 compounds including previously synthesized kinase inhibitors. 23 compounds were chosen as candidates for activity assay and their ability to inhibit the phosphorylation of DYRKtide (RRRFRPASPLRGPPK) by DYRK1A at a fixed concentration of $20 \mu \mathrm{M}$ with an ATP regenerative assay (Cook et al. ${ }^{16}$ ). The results for the most promising compounds are shown in Table 1 and all the 23 compounds are shown in the supporting information Table S1. The inhibitors had a broad range of activity: 8 compounds showed strong inhibition (remaining activity $<5 \%$ ), 8 compounds showed moderate inhibition (11\%-46\% remaining activity) and 6 compounds showed little or no inhibition (70\%-100\% remaining activity). 15 inhibitors that showed at least 50\% inhibition were titrated in decreasing concentrations $(200 \mu \mathrm{M}-20 \mathrm{nM})$ to determine the $\mathrm{IC}_{50}$ and $\mathrm{K}_{\mathrm{i}}$ values.

Compounds AC12, AC13, AC14, AC15 and AC27 were found to possess highest ability to inhibit the phosphorylation of DYRKtide, with $\mathrm{K}_{\mathrm{i}}$ values around 100-250 nM. AC7, AC24 and AC25 inhibitors showed $\mathrm{K}_{\mathrm{i}}$ values of around $326 \mathrm{nM}-570 \mathrm{nM}$. Inhibitors with identical core scaffolds revealed similar $K_{i}$ values, as seen for the two pairs AC12 and AC15 $(\sim 104$ nM and 158 nM), and AC24 and AC25 (383 nM and 575 nM, respectively). The remaining compounds (AC2, AC8, AC16, AC18, AC20, AC22, and AC23) were weaker compared to the 8 inhibitors 
discussed above and exhibited $\mathrm{K}_{\mathrm{i}}$ values ranging from $1.7 \mu \mathrm{M}$ to $>8 \mu \mathrm{M}$ (supporting information Table S1).

Table 1. Inhibitory activity of the selected most active compounds.

\begin{tabular}{|c|c|c|c|c|c|c|c|c|c|}
\hline Code & Name & $\begin{array}{l}\text { Remaining } \\
\text { activity at } \\
20 \mu \mathrm{M}(\%)\end{array}$ & $\begin{array}{l}\mathrm{IC}_{50} \\
(\mathrm{nM})\end{array}$ & $\begin{array}{c}\mathrm{K}_{\mathrm{i}} \\
(\mathrm{nM})\end{array}$ & $\begin{array}{l}\text { Kinome } \\
\text { Scan } \\
10 \mu \mathrm{M}\end{array}$ & $\begin{array}{l}\text { Kinome } \\
\text { Scan } \\
1 \mu \mathrm{M}\end{array}$ & $\begin{array}{c}\text { Cell line } \\
\text { tau } \\
\text { phosphorylation }\end{array}$ & $\begin{array}{c}\text { Cell line } \\
\text { Luciferase } \\
\text { Assay*** }\end{array}$ & $\begin{array}{l}\text { PDB } \\
\text { code }\end{array}$ \\
\hline AC22 & XMD8-49 & 24 & $>6000$ & $>2800$ & 0.7 & - & active & $5-10 \mu \mathrm{M}$ & $6 \mathrm{EIL}$ \\
\hline $\mathrm{AC23}$ & XMD8-62e & 15 & 4200 & 2015 & 1.6 & - & active & $0.5-1 \mu \mathrm{M}$ & $6 \mathrm{EIP}$ \\
\hline AC20 & HG-8-60-1 & 11 & 3500 & 1680 & 1.2 & - & active & $>20 \mu \mathrm{M}$ & $6 \mathrm{EIJ}$ \\
\hline AC25 & XMD15-27 & 4 & 1200 & 575 & 0.15 & - & active & $\dagger$ & 6EIR \\
\hline AC24 & XMD14-124 & 1.3 & 800 & 383 & 0.05 & - & active & $10-20 \mu \mathrm{M}$ & 6EIQ \\
\hline AC27 & JWC-055 & 2 & 532 & 252 & - & 1.4 & active & $0.05-0.1 \mu \mathrm{M}$ & 6EIS \\
\hline AC15 & XMD7-112 & 0 & 329 & 158 & $* *$ & - & active & $5-10 \mu \mathrm{M}$ & $6 \mathrm{EJ} 4$ \\
\hline AC12 & XMD7-117 & 0 & 216 & 104 & ** & - & active & $1-5 \mu \mathrm{M}$ & $6 \mathrm{EIF}$ \\
\hline AC28 & JWD-065* & - & - & - & 0 & - & - & - & $6 \mathrm{EIV}$ \\
\hline
\end{tabular}

$\mathrm{IC}_{50}$ values determined in the Cook assay at 25 degrees and $128 \mu \mathrm{M}$ ATP, Ki calculated with a $\mathrm{K}_{\mathrm{M}}$ value for DYRK1A of $118 \mu \mathrm{M}^{17}$. *due to solubility problems of the compound in stock solution and resulting uncertainty of the concentration, binding kinetics were not measured, however a cocrystal structure with inhibitor could be obtained. **values available for DYRK1B only ( 0.5 and 0.2 respectively). $* * *$ Concentration where inhibitory activity was above 1.5 fold the basal level. †compound failed to inhibit DYRK1A in this assay, negatively interferes with the cells. 
<smiles>NS(=O)(=O)c1ccc(-c2cnc3[nH]cc(-c4cccnc4)c3c2)cc1</smiles>

AC12<smiles>COc1ccc(N)cc1-c1cnc(N)c(C(=O)c2cccnc2)n1</smiles>

AC22<smiles>COc1cc(N2CCN(C)CC2)ccc1Nc1nc(N)c(C(=O)c2ccccc2)s1</smiles>

AC24<smiles>Nc1cccc(-c2cnc3[nH]cc(-c4cccnc4)c3c2)c1</smiles>

AC15

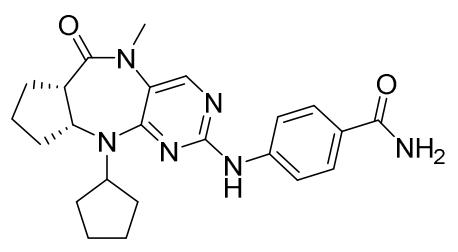

AC23

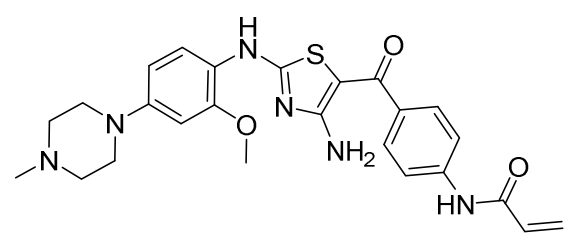

AC25

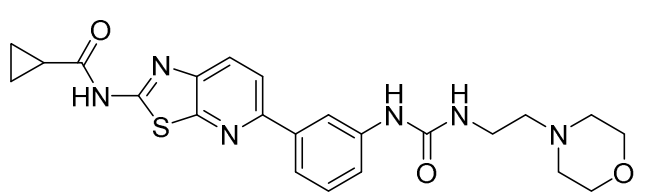

AC20<smiles>O=c1ccc2cnc3ccc(-c4cn[nH]c4)cc3c2n1-c1ccc(F)cc1C(F)(F)F</smiles>

AC27

AC28

Figure 1. Structures of the nine novel DYRK1A inhibitors, representing six different core scaffolds. AC12 and AC15 share one core structure, and AC24, AC25 and AC28 share a second type of the core structure.

\section{Tau phosphorylation inhibitory activity assay in cells}


Eight compounds that displayed inhibitory activity in vitro (see Table 1) were further tested in a cell line to establish whether they possessed the capacity to inhibit tau phosphorylation by DYRK1A. Expression vectors encoding FLAG-tagged TAU and EGFP-tagged DYRK1A were co-transfected into NCI-H1299 cells and the amount of phospho-tau protein (p-tau) was analyzed by Western blot (Figure 2 and supporting information Figure S2). Cells transfected with empty vectors were utilized as controls.

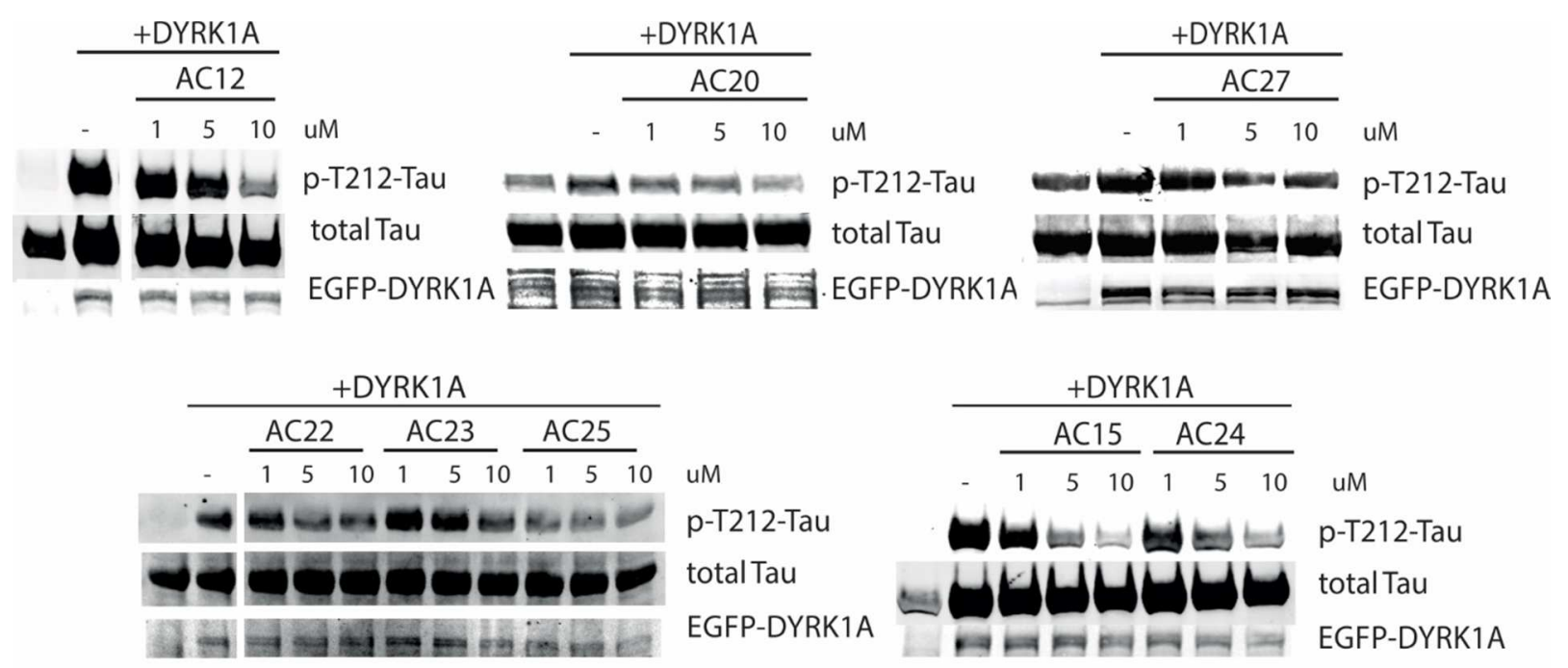

Figure 2. Inhibition of DYRK1A dependent tau T212 phosphorylation by different compounds. NCI-H1299 cells were transfected with expression vector encoding FLAG-tagged tau in combination with either empty expression vector or EGFP-tagged DYRK1A. Twenty hours after transfection the cells were incubated for 2 hours with vehicle (-) or the indicated inhibitor concentration before the cells were harvested. Phosphorylated T212 tau was detected by Westernblotting using the polyclonal anti-phospho T212 tau antibody (44-740G, Invitrogen), total FLAGtau was detected by using a monoclonal M2 anti-FLAG antibody (F1804, Sigma-Aldrich) and EGFP-DYRK1A by a polyclonal anti-GFP antibody (Sc-8334, Santa-Cruz). 
AC12, AC15, AC24 and AC25 showed a significant dose-dependent inhibition of pT212-tau phosphorylation, in contrast to AC20, AC22, AC23 and AC27. However, all these compounds inhibited pT212-tau phosphorylation. The degree of kinase inhibition observed at the protein level reflected the one seen in the in vitro activity assay. In general, compounds with $\mathrm{K}_{\mathrm{i}}$ of $600 \mathrm{nM}$ or tighter showed clear dose-response effects, while compounds with $\mathrm{K}_{\mathrm{i}}$ values ranging from 1.7 to $3 \mu \mathrm{M}$ showed inhibition but with significantly greater noise with respect to doseresponse correlation. An exception to this general observation is AC27. This compound inhibits DYRK1A in the pT212-tau phosphorylation assay, however not as potently as it would have been expected from the in vitro activity assay.

\section{Crystal structures}

The inhibitors were set up in co-crystallization trials with DYRK1A. Nine of the novel scaffolds (Figure 1) formed co-crystals. The crystal packing and asymmetric unit is similar to the previously published DYRK1A complexes with PKC412 ${ }^{17}$ or the benzothiazole fragments ${ }^{18}$, with tetramers constituting the asymmetric unit. In general, the best electron density fit is found for protomer A and the greatest disorder is seen in protomer C. Several chains in the asymmetric unit show disulfide bridge formation between the HCD motif and the activation loop cysteine. However, in many chains the cysteine residues are reduced and/or in a mixed state, with additional evidence of radiation damage due to low amplitude electron density for cysteine $\mathrm{C} 312^{17,18}$. The compounds are bound to all four protomers in the tetramer of the asymmetric unit in DYRK1A (Figure 3). One exception is compound AC22, which lacks electron density for the entire inhibitor in chain $\mathrm{C}$ of the tetramer and the ATP-pocket is empty. However, the electron 
density is clear for the other three chains. The omit difference density maps after simulated annealing for all the nine inhibitors are shown in the supporting information Figure S3. The crystallographic data and refinement statistics are summarized in supporting information Table $\mathbf{S 2}$ in the supplementary data.

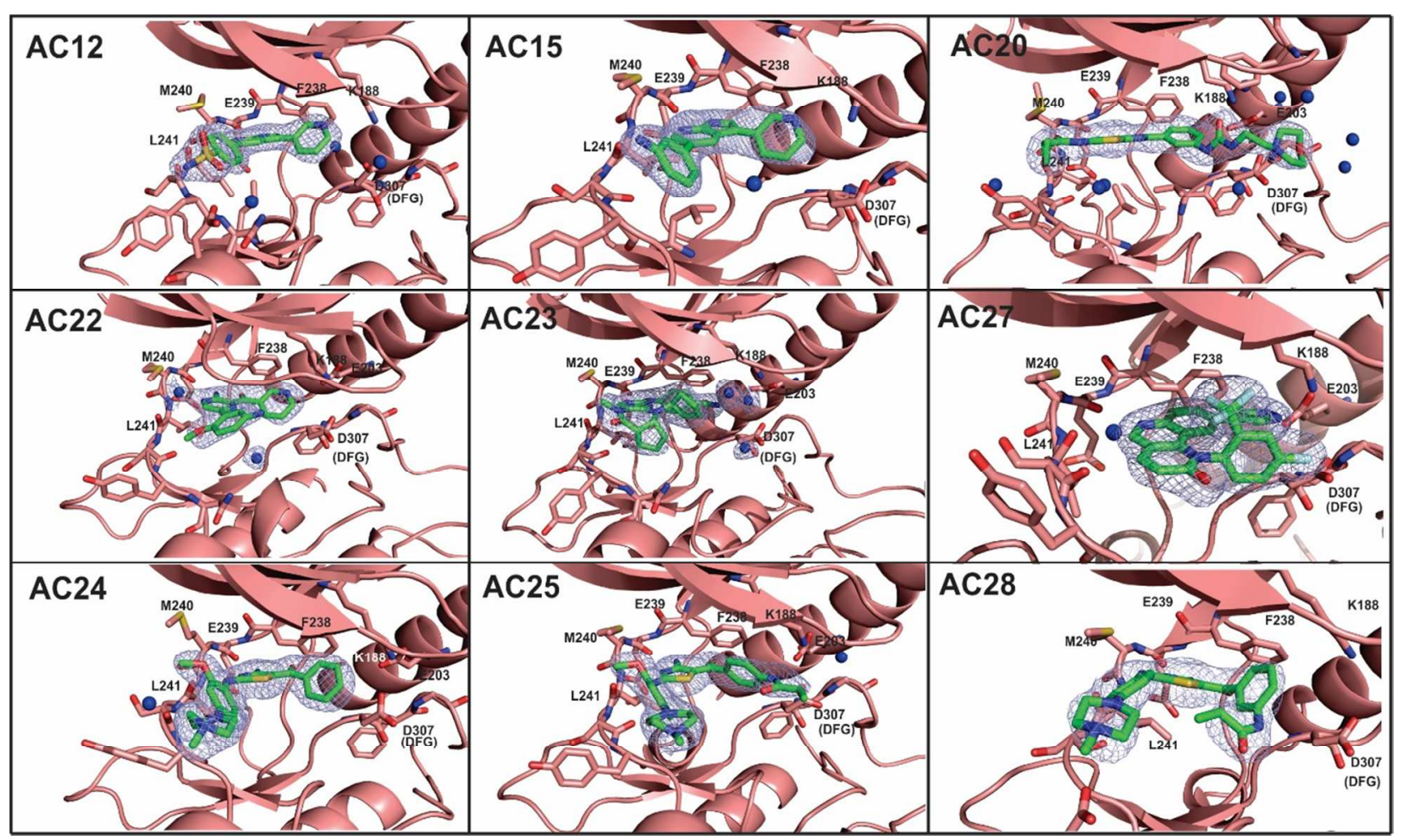

Figure 3. Binding pocket of DYRK1A bound to nine different inhibitors. The electron density for the inhibitor (2Fo-Fc map) is shown at $1 \sigma$. The inhibitors form hydrogen bonds to E239 and L241, and AC20, AC22 and AC27 form an H-bond to K188. Inhibitors AC12 and AC15 have a hydrogen bond acceptor group oriented toward K188. Most of inhibitors are shown as they bind to chain A of the four protein molecules in the asymmetric unit of DYRK1A. The two exceptions are $\mathbf{A C 2 3}$ where the inhibitor is shown bound in chain B, and AC27 with the inhibitor shown in chain D. In the AC23 crystal structure, only chain B has a water clearly visible in the electron density that could form bridging H-bonds between the inhibitor and K188 or D307. In the AC27 


\begin{abstract}
crystal structure chain D has a water molecule, which connects the inhibitor to the hinge. There is no clear electron density for a water in the other chains, however, some diffuse electron density might suggest water molecules at these positions, in the other chains too. PDB codes for DYRK1A complexes: AC12: 6EIF; AC15: 6EJ4; AC20: 6EIJ; AC22: 6EIL; AC23: 6EIP; AC24: 6EIQ; AC25: 6EIR; AC27: 6EIS; AC28: 6EIV.
\end{abstract}

The inhibitors that could be co-crystallized with DYRK1A represent six different chemical scaffolds. Inhibitors AC12 and AC15 share a 3-(3-pyridin-3-yl-1H-pyrrolo[2,3-b]pyridin-5yl)phenyl core scaffold, while inhibitors AC24, AC25 and AC28 share a 4-[4-amino-2-[2methoxy-4-(4-methylpiperazin-1-yl)anilino]-1,3-thiazole-5-carbonyl]phenyl core scaffold. AC12 and AC15 differ by the substitutions of sulfonamide (para) or amine (meta) on the terminal arene, respectively. Compound AC24 represents the core scaffold, whereby compounds AC25 and AC28 have terminal acrylamide functions added to the terminal arene at para and meta positions, respectively. AC28 differs additionally by the lack of a methoxy substitution on the central phenyl ring. The other core scaffolds are represented by compounds AC20 with 7-azathiazole, AC22 as a pyrazine, AC23 with an alkaloid, and AC27 as a substituted 1,6-phenanthroline.

With one exception, the inhibitors are typical hinge binders (Figure 3 and supporting information Figures S3, S4 and S5). AC12 and AC15 each make two hydrogen bonds to E239 (gatekeeper+1) and L241 (gatekeeper+3). The pyridine nitrogen faces the catalytic lysine K188, but the $4 \AA$ distance to the amine nitrogen is too long for a hydrogen bond. AC22 is anchored to the hinge via two hydrogen bonds, which orients the pyridine nitrogen H-bond acceptor towards the catalytic lysine K188. Compared to AC12 and AC15, the distances to K188 are shorter, including one contact at $3.2 \AA$, within the range of typical hydrogen bond distances. The crystal 
structure also shows that K188 shares a salt bridge with E203. Similarly, the aminopyrimidine functionality of AC23 is anchored to the hinge, which points the benzamide substituent towards K188, but without a direct hydrogen bond interaction. However, in chain B there is a water molecule that bridges the gap between the amide and K188. The benzamide moiety has a parallel displaced $\pi-\pi$ stacking interaction with the gatekeeper phenylalanine F238.

AC24, AC25 and AC28 make three hydrogen bonds to the hinge via the thiazole and two adjoining amines. In addition, the piperazine rings of these compounds have salt bridge interactions with D247 (the gatekeeper+8 residue). They do not interact with K188. Compared to AC24, the addition of an acrylamide group on AC25 weakens binding, and the crystal structure shows no favorable interactions, and especially no covalent binding. A superposition of AC24, AC25, and AC28 from all asymmetric unit domains show that the acrylamide groups are pushed out of the binding pocket (Figure 4). However, the electron density for the acrylamide groups are relatively weak, and some divergence in their positions is evident in the refined structures. A rotation of the terminal benzene ring of approximately 90 degrees may be seen in two binding poses for AC25. The other benzene ring of the scaffold (adjacent to the piperazine ring) is oriented differently and heterogeneously for AC28. The methoxy substituent of this ring, found in AC24 and AC25, apparently stabilizes this benzene ring compared to AC28 (Figure 4). On the other hand, the ring of inhibitor AC28 is stabilized by intramolecular $\pi-\pi$ interactions of the acrylamide double bond with the $\pi$ system of the benzene ring. 


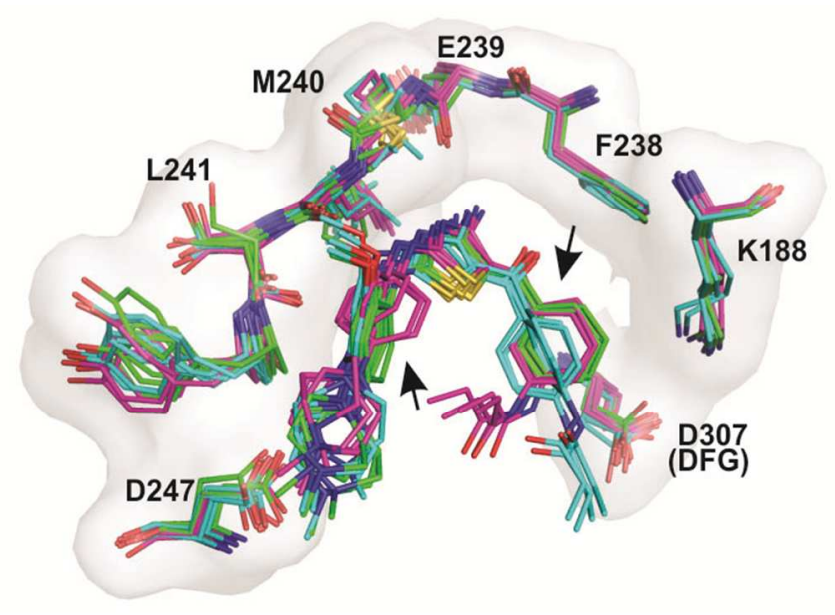

Figure 4. Superposition of the binding pockets and inhibitors of the four chains in the asymmetric unit of DYRK1A of each inhibitor: AC24 (green PDB: 6EIQ) with AC25 (cyan PDB: 6EIR) and AC28 (violet PDB: 6EIV). Although the general pose of each inhibitor remains similar, some differences are evident between the individual pockets. AC24 has the greatest conservation of geometry, while especially the acrylamide groups of AC25 and AC28 show more variation, reflected also by lower electron density for these parts.

AC20 has only a single hinge binding hydrogen bond, with L241 (gatekeeper+3), rather than a pair (including the gatekeeper+1 residue E239) that is typical for the other inhibitors. AC20 shares a hydrogen bond with the catalytic lysine K188 with its urea oxygen, and also shares a salt bridge with the DFG aspartate D307 via the morpholine nitrogen. It forms in addition a perpendicular $\pi$ stacking interaction with the gatekeeper phenylalanine. Like all the other inhibitors, AC20 binds in a typical type I binding mode.

The strongest of the inhibitors in this study, AC27 uniquely has no hydrogen bond to the hinge. It has anchoring hydrogen bonds with K188 and E203 via its diazole group, with N244 via its carbonyl group, and also with the $\mathrm{N} 292$ side chain as a C-H--O hydrogen bond with a hydrogen 
of the fluorinated arene. Additionally, a bridging water between the hinge and the inhibitor was found in the chain $\mathrm{D}$ of the tetramer. This water has a hydrogen bonding distance of $2.7 \AA$ from the 1,6-phenanthroline nitrogen, and is in contact with the main chain amide nitrogen of L241 with a distance of $2.8 \AA$ and to the carbonyl of E239 of $2.6 \AA$. The trifluoromethyl, fluorobenzyl ring is in perpendicular face-edge intramolecular contact with both the 1,6-phenanthroline and diazole rings. The trifluoromethyl group is embedded in a shallow hydrophobic pocket created by the first glycine (G166) of the glycine rich loop, the preceding I165 side chain, and the V173 side chain opposite of G166. (Figure 3) A superposition of all the inhibitors is shown in supporting information Figure S4.

\section{Kinase profiling of DYRK1A inhibitors}

We evaluated kinase selectivity profiles as determined by KinomeScan $^{\mathrm{TM}}$ binding assays against a panel of 353/402/442 distinct kinases and their mutants (Figure 5). The kinase profiling data for the inhibitors show that AC12 and AC15 are pan kinase inhibitors (with a broad spectrum of inhibition). As a consequence, these two inhibitors did not show a clear pattern of selectivity, and were generally less effective against tyrosine kinases. The kinase profiling data for remaining seven of the compounds with cocrystal structures showed the typical cross reactivities of the inhibitors between DYRK and CLK families. In addition, AC22 and AC27 show significant cross reactivities against GSK3 $\beta$, which is consistent with the kinase selectivity pattern of leucettine $\mathrm{L} 41^{19}$

AC20 exhibited good overall kinome selectivity, with a S(10) selectivity score of 0.06 at 10 $\mu \mathrm{M}$. (The S(10) selectivity index is defined as the percentage of the kinome inhibited below $10 \%$ of the control; $\mathrm{S}[10]=[$ number of kinases with $\% \mathrm{Ctrl}<10] /[$ number of kinases tested $])$. AC20 
binds CLK2 more tightly than DYRK1A. This compound bound also the tyrosine kinases ABL and PDGFR, which is unsurprising, considering that the series of compounds with this core structure were initially designed for targeting $\mathrm{BCR}-\mathrm{ABL}^{20}$.

AC22 is the only tested inhibitor that shows a stronger inhibition of GSK3 $\beta$ compared to DYRK1A. Other kinases of the CMGC group significantly inhibited by AC22 include CLK2, HIPK1/2 and CDK7. AC22 also interferes with other kinases across several families, albeit with weaker binding affinity.

AC23 exhibited rather weak and unspecific DYRK binding. The main targets of this compound belonged to the CMGC and CAMK families, with DRAK1/2 and ERK5 as the top hits.

The three thiazole compounds, AC24, AC25 and AC28, have slightly varying affinities. While AC24 had greater affinity for DYRKs compared to CLKs, the addition of the acrylamide in AC25 and AC28 shifted the profile towards CLK2, and also decreases the overall selectivity.

AC27, an analog of mTOR inhibitor Torin $2^{21}$, selectively binds to mTOR, but also CMGC family kinases and lipid kinases PIK3CG, PIK4CB, with S(10) scores of 0.03 at $1 \mu \mathrm{M}$. It possesses similar inhibition strengths against DYRK1A/B, CLK1/3 and GSK3A/B among CMGC family members. 

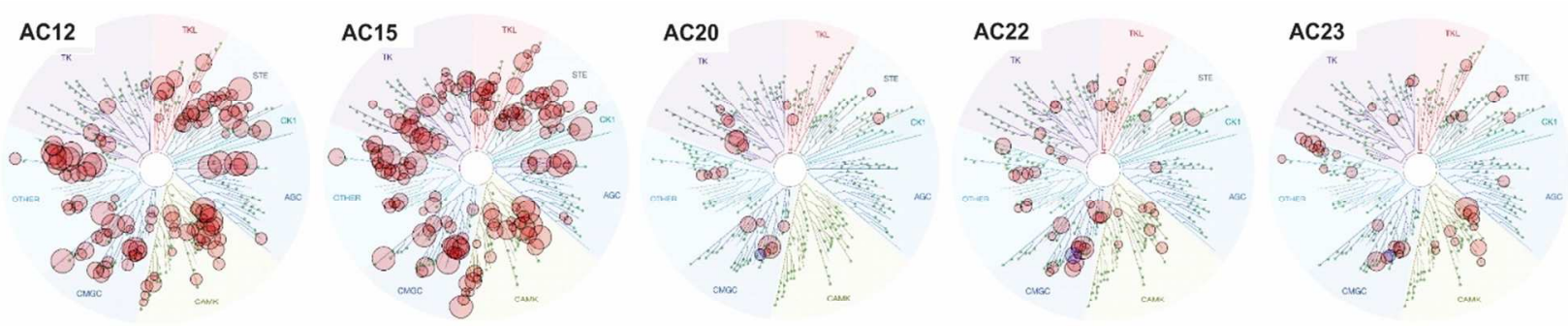

\section{NFAT Luc reporter assays}
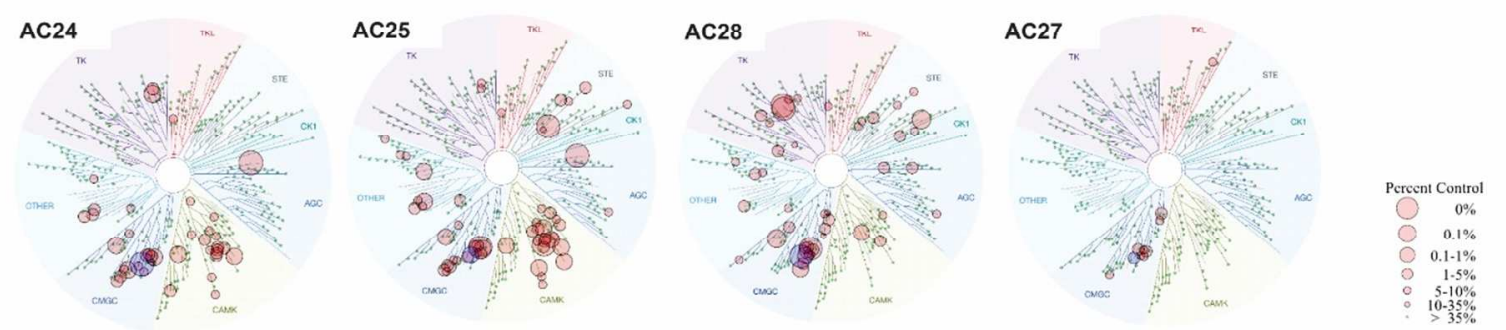

Figure 5 Kinome binding plots for the nine compounds. The levels of binding were measured at concentrations $10 \mu \mathrm{M}$ (except for AC27, measured at $1 \mu \mathrm{M}$ ).

The newly identified compounds were studied in the HEK293 cell line by introducing the NFAT luciferase activity assay (Figure 6). The compounds were titrated in increasing amounts from $0.25 \mu \mathrm{M}$ to $20 \mu \mathrm{M}$. AC27, as the most active compound, was titrated from $0.05 \mu \mathrm{M}$ to $10 \mu \mathrm{M}$. With the exception of AC25, all compounds showed activity in the tested cell line. AC12 was found to be active at concentrations up to $5 \mu \mathrm{M}$; higher concentrations of this compound led to a drop in the activity, suggesting that AC12 might be toxic at concentrations $>5 \mu \mathrm{M}$. AC15, despite sharing the same core structure of AC12, showed dose-dependent inhibition up to $20 \mu \mathrm{M}$; this compound required a minimum of $5 \mu \mathrm{M}$ to show considerable activity above the background level. This was also the case for AC20, AC22 and AC24. Based on the NFAT luciferase activity assay, the most active compounds were AC23 and AC27. Specifically, AC27 showed clear activity at $50 \mathrm{nM}$ and thus is approximately 10-fold more active than AC23 and approximately 
100-fold more active than to the other six inhibitors in this assay. The drop in the activity of AC27 at $10 \mu \mathrm{M}$ and $\mathbf{A C 2 3}$ at $20 \mu \mathrm{M}$ may suggest that these concentrations might be toxic. As mentioned above, AC25 was the only inactive compound with respect to this assay, showing an apparent dose-dependent drop in the basal activity, possibly coupled with toxicity for HEK293 cells.
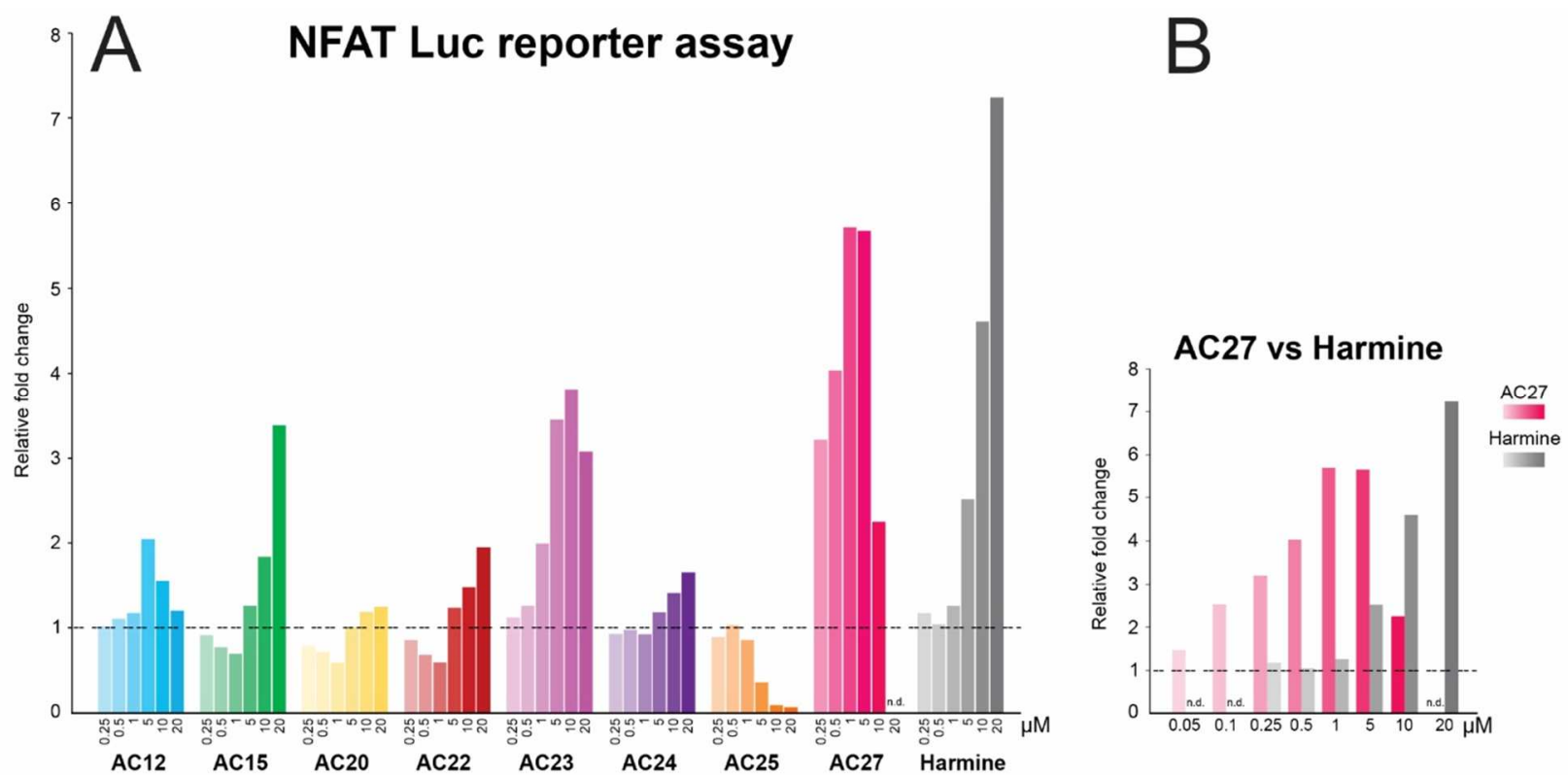

Figure 6. NFAT Luc reporter assay. The plot is normalized to the basal activity of the luciferase. Numbers indicate the fold of increase in luciferase activity upon inhibition of DYRK1A (A). The most active compound AC27 shows a 1.5 fold increase in luciferase activity at $50 \mathrm{nM}$. For comparison harmine is included in the same assay (B). Even though harmine reached a higher activity and does not display the drop in activity as $\mathbf{A C 2 7}$ at higher concentrations toward DYRK1A, AC27 is active at much lower concentrations. $100 \mathrm{nM} \mathrm{AC27}$ leads to the same activity as $5 \mu \mathrm{M}$ harmine, making AC27 nearly 50 times more active than harmine in this particular cellular assay. 


\section{DISCUSSION}

The list of potential DYRK1A inhibitors has been growing over the past few years. Diverse chemical fragments that bind to DYRK1A with high affinity have been reported ${ }^{22}$. However, none of these have advanced into clinical trials. This study presents a set of novel scaffolds with good potential for DYRK1A inhibition, evaluated using a series of structural and cellular assay experiments. AC12, AC15 and AC22 are compounds with relatively low molecular weights and can considered as fragments and classical hinge binders. In contrast to harmine, INDY $^{23}$ or recently published hydroxy- and methoxy-benzothiazole ${ }^{18}$ fragments, the distances of inhibitor atoms to the catalytic lysine or the aspartate from the DFG motive remain relatively long. On the other hand, structural variations in the physiological environment might include significant dynamic hydrogen bonding to the catalytic lysine K188, especially correlated with dynamic properties of helix C. Although AC12, AC15 and AC22 have similar molecular weights and similar binding poses with the hinge region, their binding strengths differ greatly. AC12 and AC15 were the strongest binders, while AC22 was one of the weakest that still enabled cocrystal structure determination. (The relatively weak binding of $\mathbf{A C 2 2}$ is also reflected in the fact that one of the ATP pockets of the four DYRK1A chains in the asymmetric unit of the crystal structure was empty). Detailed comparison of the structures AC12, AC15 and AC22 shows that the pyridine rings occupy the same volume, and the overlap of the nitrogen atoms anchored to the hinge is apparent (Figure 7A). However, the methoxy group of AC22 on the aniline ring most likely weakens the binding. The structure shows that the methoxy group pushes the compound away from the hinge, hence increasing intramolecular strain. 

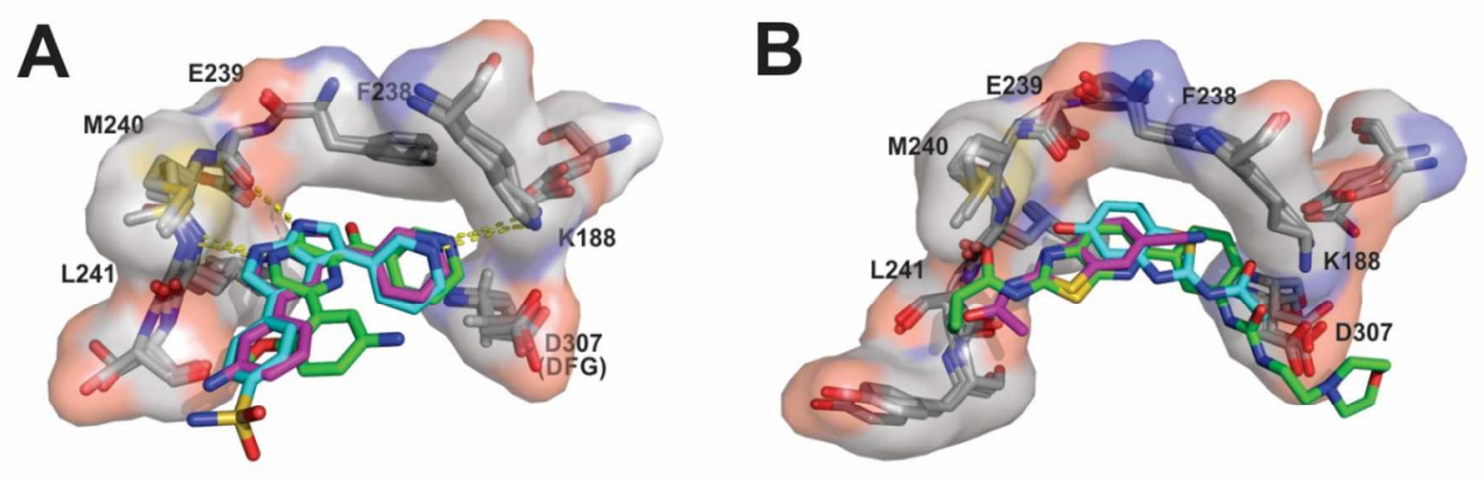

Figure 7. Orientation and interaction of the inhibitors in the binding pocket. (A) Superimposition of AC12 (cyan PDB: 6EIF) AC15 (pink PDB: 6EJ4) and AC22 (green PDB: 6EIL). The methoxy group of AC22 displaces the inhibitor away from the hinge, weakening binding. (B) Superposition of AC20 (green PDB: 6EIJ) with 5-hydroxy-benzothiazole (blue PDB: 5A3X) and 6-cyano-benzothiazole (magenta PDB: 5A4T). AC20 binds with its 5-substiuted pyridothiazole in the same orientation as the 6-cyano-benzothiazole and, unlike 5-hydroxy-benzothiazole or INDY, does not make sulfur aromatic ring interactions with the gatekeeper phenylalanine. The three compounds also have differing selectivity profiles. While AC12 and AC15 are more nearly pan kinome inhibitors (targeting many different kinases), AC22 is much more discriminating, with however a greatly reduced inhibitory strength.

The remaining inhibitors for which a cocrystal structure could be obtained are selective towards the CMGC kinase group and DYRKs. However, all show additional cross reactivity against targets outside the CMGC group.

Inhibitor AC20 inhibits DYRK1A, however the strongest inhibition of CMGC group kinases is of CLK2, and similar or stronger inhibition is seen of TK group members ABL and PDGFRB (with considerable variation across ABL mutants). AC20 is clearly hydrogen bonded to K188, 
wrapping its extended tail across and partially around the DFG motif. The pyridothiazole core structure of AC20 is similar to the benzothiazoles found in other published DYRK1A inhibitors (including $\mathrm{INDY}^{23}, \mathrm{BINDY}^{24}$, or the recently published 5- or 6- substituted benzothiazole fragments $^{18}$ ), but differs by an additional nitrogen in the six membered ring. AC20 is a 6substituted pyridothiazole; analogous to the benzothiazole interactions, the pyridothiazole binds alongside the hinge instead of making sulfur aromatic ring interactions with the gatekeeper as seen for INDY ${ }^{23}$ or the 5 -substituted fragments of benzothiazoles ${ }^{18}$ (Figure 7B).

The three thiazole compounds AC24, AC25 and AC28 show intermediate binding strengths and selectivity. Compound AC24 represents the core scaffold in this group, whereby compounds AC25 and AC28 have terminal acrylamide functions added to the terminal arene at para and meta positions, respectively. The addition of the acrylamide in AC25 and AC28 shifted the binding affinity away from DYRK towards CLK2, and also decreases the overall selectivity. Acrylamides as functional groups are typically used to introduce covalent binding of inhibitors via addition to cysteines. (These compounds were previously synthesized as inhibitors of kinases other than DYRK1A) Because of the absence of cysteine at the ATP pocket in DYRK1A, the acrylamides in AC25 and AC28 are not expected to introduce covalent binding, but nonbonded interactions still affect binding strengths. The functional acrylamide group might stabilize binding to related off-targets. AC25 was the only compound that did not inhibit DYRK1A in the NFATluc assay, instead showing toxicity.

As described above, the crystal structure of AC25 showed that the additional acrylamide was associated with a shift of its parent phenyl ring away from its position in AC24, presumably to avoid a steric clash with D307 (of DFG), but possibly colliding with V173. Two characteristics distinguish AC28 from AC24 and AC25: the acrylamide functional group at the meta position, and the lack of a 2-methoxy substituent in aniline. These properties changed the inhibition 
selectivity pattern significantly, eliminating their inhibitory activity against many CAMK family kinases, JNK kinases, and adding the binding to the pseudokinase domains of JAK1 and TYK2. Moreover, the cross reactivity towards MAST1 in the AGC group of AC24 and AC25 was lost in AC28. These clear and specific dependencies warrant further more detailed structural studies.

AC23 and AC27 have a potential bridging water molecule in the binding pocket that could be an important affinity determinant. In fact, for AC27 the water in the binding pocket is the only apparent interaction that anchors AC27 to the hinge. The waters are unambiguous only in chain B (AC23) or chain D (AC27) in the electron density of the DYRK1A tetramer. Despite the missing electron density, a water bridging interaction may however be important, because multiple bridged geometries may exist. Optimization of these compounds can take this into account (Figure 3 and 8).
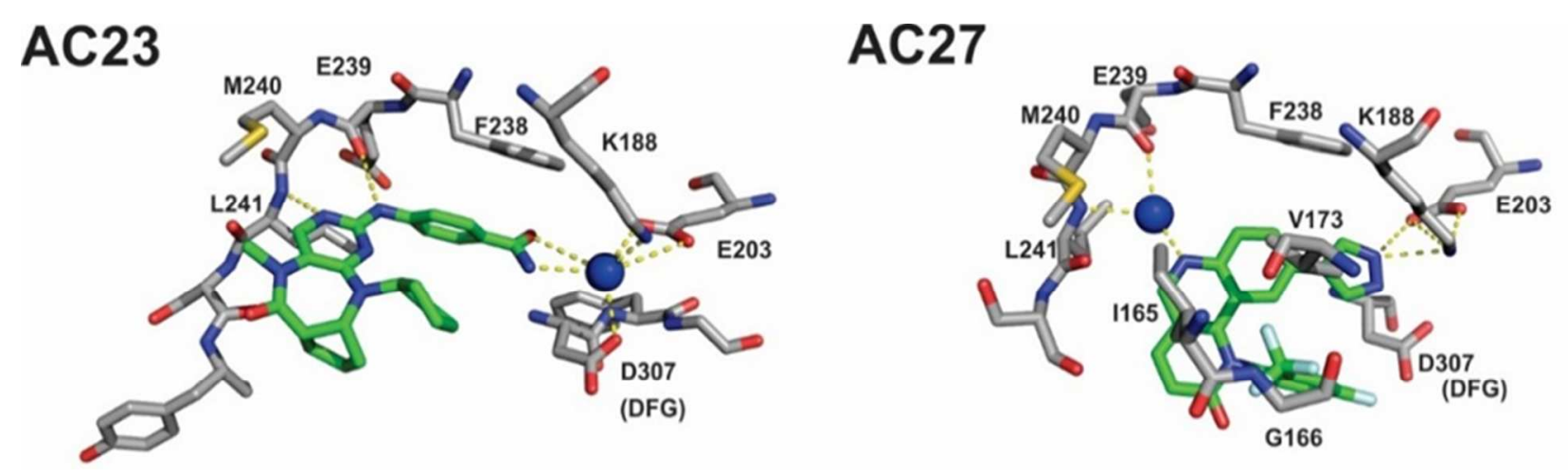

Figure 8 Water mediated binding of AC23 (PDB: 6EIP) and AC27 (PDB: 6EIS) to DYRK1A. The structure of the inhibitor in the ATP pocket of DYRK1A includes a water molecule that enables bridging interactions between the inhibitor and the K188, E203 and D307 for AC23, and between the inhibitor and the hinge carbonyl of E239 and amide nitrogen of L241 for AC27. There is no clear electron density for a water in the other chains; however, some diffuse electron density suggests it to be present there also. 
AC23 and especially AC27 were the most active compounds in the cell line assay (NFATluc, Figure 6). These compounds were active at lower concentrations compared to harmine. AC23 reached a twofold activity increase at $1 \mu \mathrm{M}$, and AC27 reached twofold activation already at $0.1 \mu \mathrm{M}$. In contrast, harmine reaches this level only at $\sim 5 \mu \mathrm{M}$, i.e. AC23 and AC27 may be seen as 5x and 50x as active, respectively. On the other hand, both AC23 and AC27 show reduced activity at concentrations above $10 \mu \mathrm{M}$. This could be an indication that these higher concentrations introduce toxicity to the cells, while harmine continues to exhibit dose dependent inhibition at these concentrations.

As mentioned above, several DYRK1A inhibitors were identified in the recent past, but none of these compounds has met the selectivity standards needed for use as probe molecules. Harmine, one of the most commonly used inhibitors in DYRK1A related research, has strong cross inhibition of monoamine oxidase that would create severe side effects. The low selectivity also makes harmine unsuitable as a probe to test DYRK1A inhibition in cell lines. Efforts to eliminate the MAO inhibition while keeping the DYRK1A inhibition lead to the harmine derivative AnnH75 $5^{25}$. Another DYRK1A inhibitor, green tea flavonol epigallocatechin-gallate (EGCG), was shown to correct cognitive deficits in Down syndrome mouse models and in humans ${ }^{26}$. However, it also potentially has multiple targets (and correspondingly is under consideration for use a broad range of disorders) and cannot be considered a DYRK specific inhibitor. The compounds EHT1610 and EHT5372 are among the most selective DYRK inhibitors identified so far ${ }^{27,}{ }^{28}$. Crystal structures of these compounds in complex with a kinase are available for DYRK2 (5LXD and 5LXC). A comparison of this scaffold to AC27, one of the more selective compound in our series, shows some remarkable similarities. First, a structural comparison of the EHT1610 and EHT5372 compound bound to DYRK2 suggests that the canonical hinge binding may be less 
essential for high affinity binding in $\mathrm{DYRK}^{28}$ as it is for AC27, because its hinge interaction is only indirect, via a bridging water molecule. Secondly, all three compounds interact with the Ploop, and the trifluoromethyl in AC27 or the 2-fluoro- and 2-chloro-benzyl group of EHT1610 and EHT5372 occupy the same space. One major difference is in the overall orientation of the inhibitors. Considering them "U" or horse-shoe shaped, the opening of the "U" for AC27 points toward the P-loop aryl F160, while the orientation is reversed for the EHT inhibitors. The benzyl rings of AC27 and the EHT inhibitors are roughly perpendicular to each other. (Figure 9)

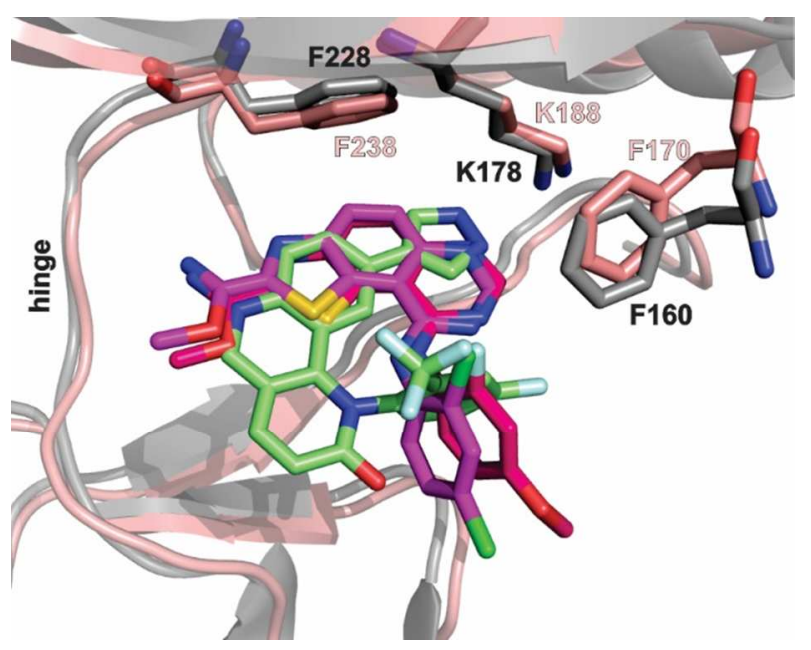

Figure 9 Comparison of the binding of AC27 (light green, PDB: 6EIS) with EHT1610 (red, PDB: 5LXD) and EHT5372 (magenta, PDB: 5LXC); (DYRK1A, salmon; DYRK2, gray).

Additional inhibitors of DYRK1A discussed in the literature include a derivative of a marine sponge alkaloid Leucettine L41, which has shown some efficacy in mice to prevent memory impairment ${ }^{29}$. Benzothiazole fragments ${ }^{18,30}$ and the independently developed benzothiazoles INDY $^{23}$ and BINDY ${ }^{24}$ are also effective inhibitors of DYRK1A. FINDY is a selective inhibitor of the kinase DYRK1A that targets its folding process $^{31}$. A detailed review article of the most 
recent DYRK1A inhibitors summarizes these results ${ }^{22}$. The lead compounds we present here, along with their binding poses as seen in the crystal structures, represent valuable additional resources for DYRK1A inhibitor development and optimization of drug likeness and selectivity profiles.

\section{CONCLUSIONS}

Twenty-two new compounds were tested for their ability to inhibit and bind to DYRK1A. These compounds belong to diverse chemical scaffolds of kinase inhibitors and their inhibitory strengths $\left(\mathrm{K}_{\mathrm{i}}\right)$ vary between $200 \mathrm{nM}$ and $>10 \mu \mathrm{M}$. Kinase profiling showed that some of the compounds (e.g. AC12 and AC15) have a broad spectrum of kinase inhibition, while others are much more specific against DYRK and CLK2. These new scaffolds offer novel opportunities to design DYRK1A inhibitors. Their inhibitory properties vary across the characterization methods and the results of in vitro vs cellular assays, especially the pT212-tau phosphorylation vs. the NFAT Luc reporter assays, were less strongly correlated for the compounds. However, this only underlines the importance to study inhibitors in multiple approaches to find the most effective inhibitor. Newly revealed binding features, such as the CH-O interaction with Asn292, or the bound waters that serve as anchors to the catalytic lysine or the hinge, may provide valuable information for optimization of these inhibitors against DYRK1A and related kinases, targeting Alzheimer's disease and diabetes. 


\title{
EXPERIMENTAL SECTION
}

1. Synthesis of the inhibitors

\begin{abstract}
$\mathbf{A C 1 5}^{32}, \mathbf{A C 2 0}^{33}, \mathbf{A C 2 3}^{34}, \mathbf{A C 2 7 ^ { 3 5 }}$ and $\mathbf{A C 2 8}{ }^{36}$ were previously reported as TRK, Bcr-Abl, ERK5, mTOR, and HIPK2 inhibitors, respectively. $\mathbf{A C 1 2}{ }^{32}$ and $\mathbf{A C 2 2}^{37}$ were synthesized following procedure described in references. AC24 and AC25 were generated from a common intermediate 1-(4-isothiocyanato-3-methoxyphenyl)-4-methylpiperazine 2, which was obtained from reaction of 2-methoxy-4-(4-methylpiperazin-1-yl)aniline with triphosgene under basic condition (Scheme 1). This isothiocyanate intermediate was allowed to react with cyanamide in the presence of $t$-BuOK, followed by addition of phenacyl bromide to give the desired 2,4 diaminothiazoles AC24 in one-pot synthesis with 96\% yield. Intermediate 3 was synthesized by similar procedure with 4-nitrophenacyl bromide and subjected to primary amine protection to generate 4. Reduction of nitro group by platinum dioxide gave rise to corresponding aniline analog, which was subjected to acrylation and Boc deprotection to afford AC25.
\end{abstract}


Scheme 1. Synthesis of AC24 and AC25

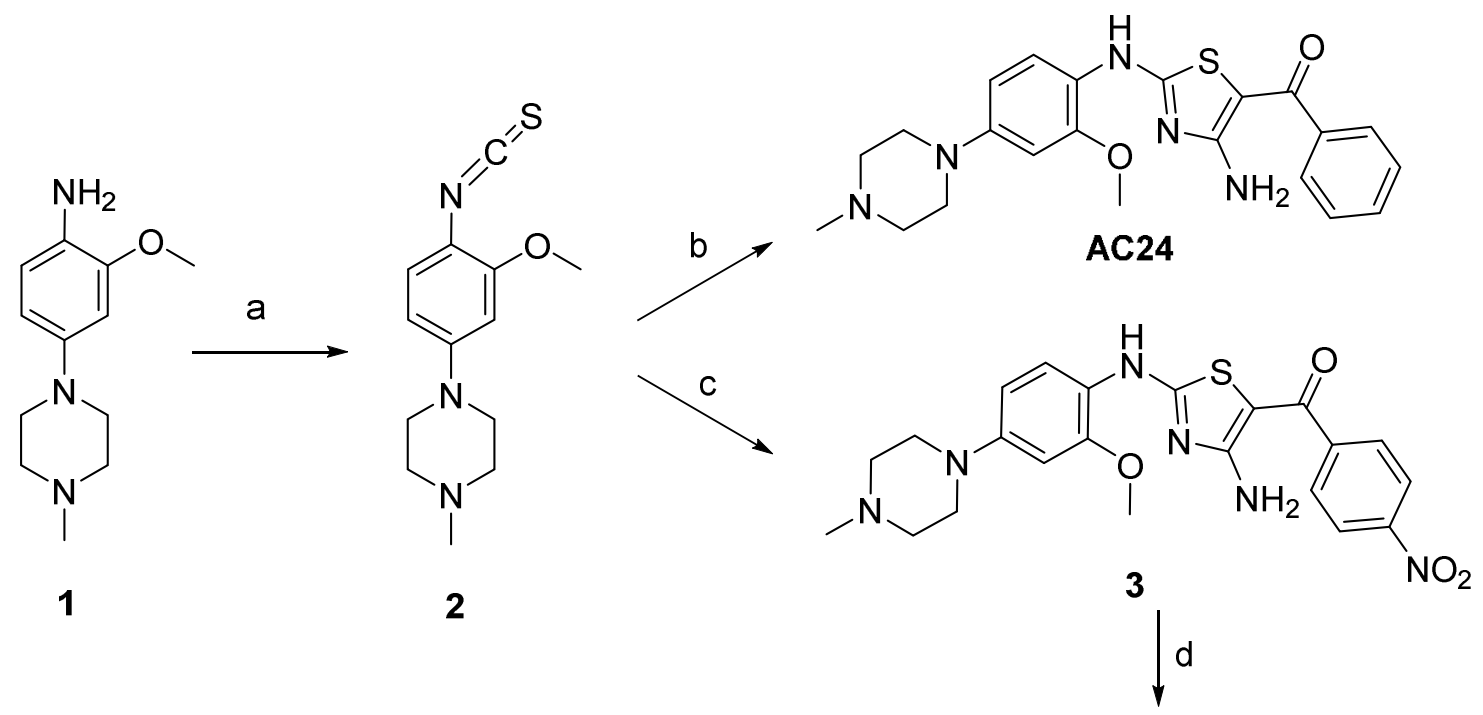<smiles>C=CC(=O)Nc1ccc(C(=O)c2sc(Nc3ccc(N4CCN(C)CC4)cc3OC)nc2N)cc1</smiles>

${ }^{a}$ Reaction conditions: (a) 1.0 equiv of thiophosgene, 5.0 equiv of TEA, $\mathrm{CHCl}_{3}, \mathrm{rt}, 3 \mathrm{~h}, 94 \%$; (b) 1 ) 2.4 equiv of $\mathrm{NH}_{2} \mathrm{CN}, 1.5$ equiv of $t$-BuOK, acetonitrile, $0{ }^{\circ} \mathrm{C}$ to $\left.\mathrm{rt}, 1 \mathrm{~h} ; 2\right) 1.0$ equiv of 2-bromo1-phenylethan-1-one, rt, $4 \mathrm{~h}, 96 \%$; (c) 1$) 2.4$ equiv of $\mathrm{NH}_{2} \mathrm{CN}, 1.5$ equiv of $t$-BuOK, acetonitrile, $0{ }^{\circ} \mathrm{C}$ to rt, $1 \mathrm{~h}$; 2) 1.0 equiv of 2-bromo-1-(4-nitrophenyl)ethan-1-one, rt, $4 \mathrm{~h}, 47 \%$; (d) 1.0 equiv of (Boc) $)_{2} \mathrm{O}, 0.3$ equiv of DMAP, 2.0 equiv of DIEA, $\mathrm{CH}_{2} \mathrm{Cl}_{2}$, rt, 2 days, $89 \%$; (e) 1$) 1.05$ equiv of $\mathrm{PtO}_{2}, \mathrm{H}_{2}, \mathrm{MeOH}, \mathrm{rt}, 1 \mathrm{~h}$; 2) 1.27 equiv acryloyl chloride, $\mathrm{CH}_{2} \mathrm{Cl}_{2}, 0{ }^{\circ} \mathrm{C}, 0.5 \mathrm{~h}$; 3) TFA, $0{ }^{\circ} \mathrm{C}$ to rt, $1 \mathrm{~h}, 46 \%$. 


\section{Chemistry.}

Unless otherwise noted, reagents and solvents were obtained from commercial suppliers and were used without further purification. ${ }^{1} \mathrm{H}$ NMR and ${ }^{13} \mathrm{C}$ NMR were recorded on Bruker Ascend 500. ${ }^{1} \mathrm{H}$ NMR spectra were $500 \mathrm{MHz}$, and chemical shifts are reported in parts per million $(\mathrm{ppm}, \delta)$ downfield from tetramethylsilane (TMS). Coupling constants $(J)$ are reported in Hz. Spin multiplicities are described as s (singlet), $\mathrm{d}$ (doublet), $\mathrm{t}$ (triplet), $\mathrm{m}$ (multiplet), and br (broad). IR spectra were recorded on a Bruker ALPHA II Platinum single reflection diamond ATR Module. High-resolution mass spectra (HRMS) were recorded on a Bruker Impact HD qTOF Mass Spectrometer. Preparative HPLC was performed on a Waters Symmetry C18 column (19 x $50 \mathrm{~mm}, 5 \mu \mathrm{M})$ using a gradient of $5-95 \%$ acetonitrile in water containing $0.05 \%$ trifluoroacetic acid (TFA) over $8 \mathrm{~min}(10 \mathrm{~min}$ run time) at a flow rate of $30 \mathrm{~mL} / \mathrm{min}$. Analytic HPLC was performed on a SunFire C18 column $(4.6 \times 150 \mathrm{~mm}, 3.5 \mu \mathrm{M})$ using a gradient of 595\% acetonitrile in water containing $0.05 \%$ trifluoroacetic acid (TFA) over $15 \min$ (17 min run time) at a flow rate of $1.0 \mathrm{~mL} / \mathrm{min}$. Purities of compounds were greater than $95 \%$ unless indicated otherwise, as determined by analytical HPLC.

\section{4-[3-(Pyridin-3-yl)-1H-pyrrolo[2,3-b]pyridin-5-yl]benzene-1-sulfonamide (XMD7-117,}

AC-12). ${ }^{1} \mathrm{H}$ NMR (500 MHz, DMSO- $\left.d_{6}\right) \delta 12.47$ (s, $\left.1 \mathrm{H}\right), 9.36$ (br, $\left.1 \mathrm{H}\right), 9.08-8.48(\mathrm{~m}, 4 \mathrm{H}), 8.29$ $(\mathrm{d}, J=2.0 \mathrm{~Hz}, 1 \mathrm{H}), 8.05(\mathrm{~d}, J=8.3 \mathrm{~Hz}, 2 \mathrm{H}), 7.99-7.77(\mathrm{~m}, 3 \mathrm{H}), 7.43(\mathrm{~s}, 2 \mathrm{H}) .{ }^{13} \mathrm{C}$ NMR $(126$ MHz, DMSO-d $\left.{ }_{6}\right) \delta 149.5,143.2,143.2,142.2,142.5,142.4,138.6,128.5,128.1,127.8,126.7$, 126.6, 117.4, 110.3. IR $\mathbf{v}_{\text {max }}$ (neat): 3299, 3007, 2862, 1586, 1527, 1476, 1329, 1156, 1095, 909, 670, 589, $544 \mathrm{~cm}^{-1}$. HRMS (ESI) $\mathrm{m} / z$ : calcd for $\mathrm{C}_{18} \mathrm{H}_{14} \mathrm{~N}_{4} \mathrm{O}_{2} \mathrm{~S}[\mathrm{M}+\mathrm{H}]^{+}, 351.0910$; found 351.0909 . 
5-(5-Amino-2-methoxyphenyl)-3-(pyridine-3-carbonyl)pyrazin-2-amine (XMD8-49, AC22). ${ }^{1} \mathrm{H}$ NMR $\left(500 \mathrm{MHz}, \mathrm{CD}_{3} \mathrm{OD}\right) \delta 9.27(\mathrm{~d}, J=1.2 \mathrm{~Hz}, 1 \mathrm{H}), 8.84(\mathrm{~s}, 1 \mathrm{H}), 8.70(\mathrm{~d}, J=4.9 \mathrm{~Hz}$, $1 \mathrm{H}), 8.47(\mathrm{~d}, J=7.9 \mathrm{~Hz}, 1 \mathrm{H}), 7.61(\mathrm{dd}, J=7.9,5.0 \mathrm{~Hz}, 1 \mathrm{H}), 7.10(\mathrm{~d}, J=2.8 \mathrm{~Hz}, 1 \mathrm{H}), 6.94(\mathrm{~d}, J=$ $8.7 \mathrm{~Hz}, 1 \mathrm{H}), 6.79(\mathrm{dd}, J=8.6,2.8 \mathrm{~Hz}, 1 \mathrm{H}), 3.83(\mathrm{~s}, 3 \mathrm{H}) .{ }^{13} \mathrm{C} \mathrm{NMR}\left(126 \mathrm{MHz}, \mathrm{CD}_{3} \mathrm{OD}\right) \delta 192.9$, $154.7,150.8,150.7,150.3,149.6,141.0,139.9,138.7,134.5,127.6,125.9,123.3,117.1,116.9$, 113.00, 55.3. IR $\mathbf{v}_{\max }$ (neat): 3424, 3252, 3124, 2836, 1632, 1585, 1503, 1222, 1207, 1032, 798, $679,442 \mathrm{~cm}^{-1}$. HRMS (ESI) $m / z$ : calcd for $\mathrm{C}_{17} \mathrm{H}_{15} \mathrm{~N}_{5} \mathrm{O}_{2}[\mathrm{M}+\mathrm{H}]^{+}, 322.1299$; found 322.1299.

1-(4-Isothiocyanato-3-methoxyphenyl)-4-methylpiperazine (2) To a solution of 2-methoxy4-(4-methylpiperazin-1-yl)aniline (1) $(663 \mathrm{mg}, 3.0 \mathrm{mmol})$ and triethylamine $(2.10 \mathrm{~mL}, 15.0$ mmol) in $10 \mathrm{~mL} \mathrm{CHCl}$ at $0{ }^{\circ} \mathrm{C}$, thiophosgene $(0.23 \mathrm{~mL}, 3.0 \mathrm{mmol})$ was added. After 15 minutes, the reaction mixture was stirred at room temperature. Once the reaction completed (about 3 hours), the reaction mixture was diluted with ethyl acetate, washed with ice water and brine. After the organic layer was dried with $\mathrm{MgSO}_{4}$, the solvent was removed. The crude product of title compound (747 mg, 94\%) was used directly for next step without purification (84.9\% purity). ${ }^{1} \mathrm{H}$ NMR $\left(500 \mathrm{MHz}, \mathrm{CDCl}_{3}\right) \delta 6.93(\mathrm{~d}, J=8.6 \mathrm{~Hz}, 1 \mathrm{H}), 6.38-6.26(\mathrm{~m}, 2 \mathrm{H}), 3.81(\mathrm{~s}$, $3 \mathrm{H}), 3.20(\mathrm{t}, J=5.1 \mathrm{~Hz}, 4 \mathrm{H}), 2.56(\mathrm{t}, J=5.0 \mathrm{~Hz}, 4 \mathrm{H}), 2.33(\mathrm{~s}, 3 \mathrm{H}) .{ }^{13} \mathrm{C} \mathrm{NMR}\left(126 \mathrm{MHz}, \mathrm{CDCl}_{3}\right)$ $\delta 156.7,151.3,137.8,128.8,126.1,107.4,99.6,55.9,54.7,48.4,45.9$. IR $v_{\max }$ (neat): 2936, $2794,2703,2099,1595,1565,1510,1417,1263,1252,1211,1203,1134,1025,1008,969,815$, $556 \mathrm{~cm}^{-1}$. HRMS (ESI) $\mathrm{m} / z$ : calcd for $\mathrm{C}_{13} \mathrm{H}_{17} \mathrm{~N}_{3} \mathrm{OS}[\mathrm{M}+\mathrm{H}]^{+}, 264.1165$; found 264.1165. HPLC: $84.9 \%$ at $254 \mathrm{nM}$.

\section{(4-Amino-2-((2-methoxy-4-(4-methylpiperazin-1-yl)phenyl)amino)thiazol-5-yl)(phenyl)}

methanone (XMD14-124, AC24). To a solution of 1-(4-isothiocyanato-3-methoxyphenyl)-4methylpiperazine $(2)(30 \mathrm{mg}, 0.12 \mathrm{mmol})$ in $1.0 \mathrm{~mL}$ acetonitrile at $0{ }^{\circ} \mathrm{C}$ cyanamide $(10 \mathrm{mg}$, $0.24 \mathrm{mmol})$ was added, followed by potassium tert-butoxide $(0.15 \mathrm{~mL} 1 \mathrm{M}$ solution in $\mathrm{THF}$, 
$0.15 \mathrm{mmol})$. After 10 minutes, the reaction mixture was stirred at room temperature. Once the reaction completed (about one hour), 2-bromo-1-phenylethan-1-one (20 mg, $0.1 \mathrm{mmol}$ ) was added at room temperature. The reaction completed in about four hours. The reaction mixture was diluted with ethyl acetate, washed with ice water and brine. After the organic layer was dried with $\mathrm{MgSO}_{4}$, the solvent was removed and the residue was purified by column purification $\left(\mathrm{CH}_{2} \mathrm{Cl}_{2} / 3.5 \mathrm{~N}\right.$ Ammonia in $\left.\mathrm{MeOH}\right)$ to afford desired compound (40.7 mg, 96\%). ${ }^{1} \mathrm{H}$ NMR (500 $\left.\mathrm{MHz}, \mathrm{CD}_{3} \mathrm{OD}\right) \delta 7.56-7.51(\mathrm{~m}, 2 \mathrm{H}), 7.47(\mathrm{~d}, J=8.7 \mathrm{~Hz}, 1 \mathrm{H}), 7.40-7.24(\mathrm{~m}, 3 \mathrm{H}), 6.56(\mathrm{~d}, J=$ $2.5 \mathrm{~Hz}, 1 \mathrm{H}), 6.44(\mathrm{dd}, J=8.8,2.5 \mathrm{~Hz}, 1 \mathrm{H}), 3.75(\mathrm{~s}, 3 \mathrm{H}), 3.18(\mathrm{t}, J=5.0 \mathrm{~Hz}, 4 \mathrm{H}), 2.74(\mathrm{t}, J=5.0$ $\mathrm{Hz}, 4 \mathrm{H}), 2.42(\mathrm{~s}, 3 \mathrm{H}) .{ }^{13} \mathrm{C} \mathrm{NMR}\left(126 \mathrm{MHz}, \mathrm{CD}_{3} \mathrm{OD}\right) \delta 183.8,172.5,167.00,152.8,150.1,141.9$, $130.1,128.0,126.6,124.4,120.5,107.6,100.4,94.4,54.9,54.2,48.1,44.0$. IR $\mathbf{v}_{\max }$ (neat): 2806 1602, 1537, 1213, 1350, 1262, 1241, 737, 699, $509 \mathrm{~cm}^{-1}$. HRMS (ESI) $\mathrm{m} / z$ : calcd for $\mathrm{C}_{22} \mathrm{H}_{25} \mathrm{~N}_{5} \mathrm{O}_{2} \mathrm{~S}[\mathrm{M}+\mathrm{H}]^{+}, 424.1802$; found 424.1802 .

\section{(4-Amino-2-((2-methoxy-4-(4-methylpiperazin-1-yl)phenyl)amino)thiazol-5-yl)(4-}

nitrophenyl)methanone (3). To a solution of 1-(4-isothiocyanatophenyl)-4-methylpiperazine (2) (157.8 $\mathrm{mg}, 0.6 \mathrm{mmol})$ in $5.0 \mathrm{~mL}$ acetonitrile at $0{ }^{\circ} \mathrm{C}$ cyanamide $(50 \mathrm{mg}, 1.19 \mathrm{mmol})$ was added, followed by potassium tert-butoxide $(0.75 \mathrm{~mL} 1 \mathrm{M}$ solution in THF). After 10 minutes, the reaction mixture was stirred at room temperature. Once the reaction completed (about one hour), 2-bromo-1-(4-nitrophenyl)ethan-1-one $(122 \mathrm{mg}, 0.5 \mathrm{mmol})$ was added at room temperature. The reaction completed in about four hours. The reaction mixture was diluted with ethyl acetate, washed with ice water and brine. After the organic layer was dried with $\mathrm{MgSO}_{4}$, the solvent was removed and the residue was purified by column purification $\left(\mathrm{CH}_{2} \mathrm{Cl}_{2} / 3.5 \mathrm{~N}\right.$ Ammonia in $\left.\mathrm{MeOH}\right)$ to afford desired compound (219 mg, 47\%). ${ }^{1} \mathrm{H}$ NMR $\left(500 \mathrm{MHz}, \mathrm{CDCl}_{3}\right) \delta 8.17(\mathrm{~d}, J=8.3 \mathrm{~Hz}$, 2H), $7.93(\mathrm{~s}, 1 \mathrm{H}), 7.78(\mathrm{~d}, J=8.3 \mathrm{~Hz}, 2 \mathrm{H}), 7.39(\mathrm{~d}, J=8.6 \mathrm{~Hz}, 1 \mathrm{H}), 6.49-6.36(\mathrm{~m}, 2 \mathrm{H}), 3.78(\mathrm{~s}$, 
$3 \mathrm{H}), 3.13(\mathrm{t}, J=5.0 \mathrm{~Hz}, 4 \mathrm{H}), 2.50(\mathrm{t}, J=5.0 \mathrm{~Hz}, 4 \mathrm{H}), 2.28(\mathrm{~s}, 3 \mathrm{H}) \cdot{ }^{13} \mathrm{C} \mathrm{NMR}\left(126 \mathrm{MHz}, \mathrm{CDCl}_{3}\right)$ $\delta 181.5,170.8,165.9,151.2,150.2,148.7,147.3,128.2,123.7,122.1,119.5,107.7,100.0,55.8$ 55.0, 49.1, 46.1. IR $\boldsymbol{v}_{\max }$ (neat): 2808, 1597, 1533, 1417, 1339, 1262, 1242, 972, 735, 705, 473 $\mathrm{cm}^{-1}$. HRMS (ESI) $m / z$ : calcd for $\mathrm{C}_{22} \mathrm{H}_{24} \mathrm{~N}_{6} \mathrm{O}_{4} \mathrm{~S}[\mathrm{M}+\mathrm{H}]^{+}, 469.1653$; found 469.1652 .

tert-Butyl (2-((2-methoxy-4-(4-methylpiperazin-1-yl)phenyl)amino)-5-(4-nitrobenzoyl)

thiazol-4-yl)carbamate (4). To a stirred suspension of (4-amino-2-((2-methoxy-4-(4methylpiperazin-1-yl)phenyl)amino) thiazol-5-yl)(4-nitrophenyl)methanone (3) (72 mg, $0.15 \mathrm{mmol})$ in $4.0 \mathrm{~mL}$ dichloromethane at room temperature, 4-dimethylaminopyridine $(6.0 \mathrm{mg}$, $0.05 \mathrm{mmol})$, N,N-diisopropylethylamine $(0.06 \mathrm{~mL}, 0.3 \mathrm{mmol})$, and di-tert-butyl dicarbonate (34 $\mathrm{mg}, 0.15 \mathrm{mmol}$ ) were added. After 10 minutes, the reaction mixture turned clear. When the reaction completed (about 2 days), the reaction mixture was concentrated and the residue was purified by column purification $\left(\mathrm{CH}_{2} \mathrm{Cl}_{2} / 3.5 \mathrm{~N}\right.$ Ammonia in $\left.\mathrm{MeOH}\right)$ to afford titled compound (93.1\% purity, $77 \mathrm{mg}, 89 \%) .{ }^{1} \mathrm{H}$ NMR (500 MHz, CD 3 OD) $\delta 8.39$ (d, $\left.J=8.4 \mathrm{~Hz}, 2 \mathrm{H}\right), 7.99$ (d, $J$ $=8.4 \mathrm{~Hz}, 2 \mathrm{H}), 7.14(\mathrm{~d}, J=8.5 \mathrm{~Hz}, 1 \mathrm{H}), 6.77(\mathrm{~d}, J=2.5 \mathrm{~Hz}, 1 \mathrm{H}), 6.68(\mathrm{dd}, J=8.7,2.5 \mathrm{~Hz}, 1 \mathrm{H})$, $4.07-3.92(\mathrm{~m}, 2 \mathrm{H}), 3.84(\mathrm{~s}, 3 \mathrm{H}), 3.72-3.60(\mathrm{~m}, 2 \mathrm{H}), 3.32-3.05(\mathrm{~m}, 4 \mathrm{H}), 3.02(\mathrm{~s}, 3 \mathrm{H}), 1.40(\mathrm{~s}$ 9H). ${ }^{13} \mathrm{C}$ NMR (126 MHz, CD $\left.\mathrm{OD}\right) \delta 184.0,167.9,163.9,155.4,152.7,151.5,149.1,146.8$, 129.7, $128.2,123.4,120.5,107.8,100.7,83.9,54.9,53.3,46.5,42.2,26.6$. IR $\mathbf{v}_{\text {max }}$ (neat): 1717 $1676,1610,1520,1345,1293,1127,1091,847,433 \mathrm{~cm}^{-1}$. HRMS (ESI) $\mathrm{m} / z$ : calcd for $\mathrm{C}_{27} \mathrm{H}_{32} \mathrm{~N}_{6} \mathrm{O}_{6} \mathrm{~S}[\mathrm{M}+\mathrm{H}]^{+}, 569.2177$; found 569.2182.

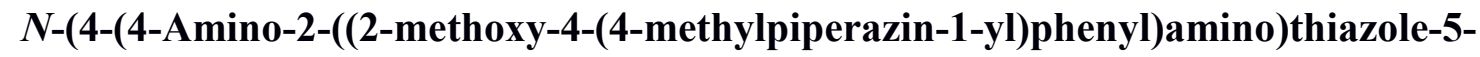

carbonyl)phenyl)acrylamide (XMD15-27, AC25). A suspension of tert-butyl (2-((2-methoxy4-(4-methylpiperazin-1-yl)phenyl)amino)-5-(4-nitrobenzoyl)thiazol-4-yl)carbamate (4) (50 mg, $0.088 \mathrm{mmol})$ and platinum dioxide $(21 \mathrm{mg}, 0.093 \mathrm{mmol})$ in $6.0 \mathrm{~mL}$ methanol was stirred at room temperature under hydrogen atmosphere. After one hour, the reaction mixture was filtered. The 
solvent of the filtrate was removed and the residue was dried under vacuum. The crude product was used directly without purification. To its solution in $3.0 \mathrm{~mL}$ dichloromethane at $0{ }^{\circ} \mathrm{C}$ acryloyl chloride $(9 \mu \mathrm{L}, 0.11 \mathrm{mmol})$ was added. Once the reaction completed (in about 30 minutes), 1.0 $\mathrm{mL}$ trifluoroacetic acid was added at $0{ }^{\circ} \mathrm{C}$. The temperature of reaction mixture gradually increased to room temperature. When the reaction completed, reaction mixture was concentrated and the resulting residue was purified by reverse-phase prep-HPLC using a water $(0.05 \% \mathrm{TFA}) / \mathrm{methanol}(0.05 \% \mathrm{TFA})$ gradient to afford the desired compound $(20.5 \mathrm{mg}, 46 \%)$. ${ }^{1} \mathrm{H}$ NMR (500 MHz, DMSO-d $) \delta 10.32(\mathrm{~s}, 1 \mathrm{H}), 9.86(\mathrm{~s}, 1 \mathrm{H}), 7.71(\mathrm{t}, J=9.8,8.3 \mathrm{~Hz}, 2 \mathrm{H}), 7.59$ $(\mathrm{d}, J=8.3 \mathrm{~Hz}, 2 \mathrm{H}), 7.41(\mathrm{~s}, 1 \mathrm{H}), 6.62(\mathrm{~d}, J=2.5 \mathrm{~Hz}, 1 \mathrm{H}), 6.51-6.41(\mathrm{~m}, 2 \mathrm{H}), 6.28(\mathrm{dd}, J=17.0$, $2.0 \mathrm{~Hz}, 1 \mathrm{H}), 5.79(\mathrm{dd}, J=10.0,1.9 \mathrm{~Hz}, 1 \mathrm{H}), 3.79(\mathrm{~s}, 3 \mathrm{H}), 3.17(\mathrm{t}, J=4.9 \mathrm{~Hz}, 4 \mathrm{H}), 2.45(\mathrm{t}, J=5.0$ $\mathrm{Hz}, 4 \mathrm{H}), 2.23(\mathrm{~s}, 3 \mathrm{H}) .{ }^{13} \mathrm{C}$ NMR (126 MHz, DMSO-d 6$) \delta 181.8,166.7,163.8,141.1,137.5$, $132.2,128.1,127.8,119.1,107.25,100.3,92.9,56.0,55.1,48.5,46.2$. IR v max (neat): 2920, $2849,1672,1594,1517,1409,968,762,727 \mathrm{~cm}^{-1}$. HRMS (ESI) $m / z$ : calcd for $\mathrm{C}_{25} \mathrm{H}_{28} \mathrm{~N}_{6} \mathrm{O}_{3} \mathrm{~S}[\mathrm{M}$ $+\mathrm{H}]^{+}, 493.2016$; found 493.2016.

\section{Expression and purification}

A DYRK1A construct comprising the kinase domain (126-490) was cloned into pEXP17 with $\mathrm{N}$-terminal $6 \mathrm{x}(\mathrm{HIS})$ affinity tags and TEV protease cleavage sites ${ }^{17}, 18$. Expression was done in shaker flask cultures overnight at $17.8^{\circ} \mathrm{C}$ in TB media. For the purification of DYRK1A the cells were resuspended in a lysis buffer containing $50 \mathrm{mM}$ sodium phosphate buffer $\mathrm{pH} 8.0$ with 500 $\mathrm{mM} \mathrm{NaCl}$ and of $0.5 \%$ Tween 20 . Purification was done via NiNTA columns and an imidazole gradient $(10-500 \mathrm{mM})$, followed by a TEV cleavage overnight and a second NiNTA to separate the kinase from uncut protein and the protease. Final purification for DYRK1A was done via size exclusion chromatography (SEC buffer: 50 mM MOPS pH 6.8, $50 \mathrm{mM} \mathrm{KCl,} 2 \mathrm{mM} \beta$-Me). 


\section{Crystallization}

DYRK1A was concentrated to $7-10 \mathrm{mg} / \mathrm{mL}$ in SEC buffer and mixed with inhibitor solutions in DMSO to achieve approximately a 5-10 fold excess of inhibitor. The final concentration of DMSO was $\sim 5 \%$. The protein/inhibitor mixture was than mixed 1:1 with the crystallization solution (100 mM KSCN, 50-100 mM LiCl (or NaCl, or $\mathrm{KCl}$ ), 10-20\% PEG3350) for a final drop size of $4 \mu \mathrm{l}$. Crystallization was done in 24 well hanging drop plates. Octahedron shaped crystals appeared within 1-7 days at room temperature. Crystals were cryo-protected with 30\% ethylene glycol and flash frozen in liquid nitrogen.

\section{Structure solving and refinement}

Crystals were measured at the ESRF Grenoble, France. The images were integrated using the software XDSapp ${ }^{38}$. The structure was solved by molecular replacement using the DYRK1A structure 5A4T as a search model. Refinement was done by Phenix ${ }^{39}$ and the $\mathrm{CCP} 4{ }^{40}$ program Refmac $5^{41}$. The waters were placed by the program Coot $0.7 .2^{42}$. The crystallographic data and model statistics are summarized in Table S2.

\section{Activity assay}

The determination of the $\mathrm{IC}_{50}$ constants for DYRK1A was done by an ATP regenerative NADH consuming assay ${ }^{16}$. The enzyme velocity was measured at $340 \mathrm{~nm}$ over a time period of $300 \mathrm{~s}$ at room temperature. ATP and the peptide RRRFRPASPLRGPPK (DYRKtide) were used as substrates. The reaction mixture was composed of $75 \mu 1$ of $100 \mathrm{mM}$ MOPS buffer $\mathrm{pH} 6.8,10$ $\mathrm{mM} \mathrm{KCl}, 10 \mathrm{mM} \mathrm{MgCl}, 1 \mathrm{mM}$ phosphoenolpyruvate, $1 \mathrm{mM}$ DYRKtide, $1 \mathrm{mM} \beta-\mathrm{ME}$, 15 units/mL lactate dehydrogenase, 10 units/ml pyruvate kinase and $10.7 \mathrm{mM} \mathrm{NADH.} 10 \mu 1$ of 
$\sim 5-20 \mu \mathrm{M}$ DYRK1A, $2 \mu \mathrm{L}$ of inhibitor in DMSO in concentrations ranging from $4 \mathrm{nM}$ and 20 $\mu \mathrm{M}$ and $10 \mu \mathrm{L}$ of ATP $128 \mu \mathrm{M}$ were added to a total volume of $97 \mu \mathrm{L}$. All measurements were done in triplicate at room temperature. All other in vitro kinase assays were conducted using the SelectScreen Kinase Profiling Service at Thermo Fisher Scientific (Madison, WI). The protocols are available from Thermo Fisher Scientific website.

7. Cell culture, transfections and treatments

DNA constructs: The plasmid encoding EGFP-tagged DYRK1A has been described earlier ${ }^{43}$ and was a kind gift from Dr. D'Arcangelo (Rutgers, USA). The expression vector encoding the FLAG-tagged tau ${ }^{44}$ was a kind gift from Dr. Paudel (McGill University, Canada).

NCI-H1299 cells (ATCC-CRL-5803) were maintained in Dulbecco's modified Eagle's medium supplemented with 10\% fetal bovine serum (Invitrogen), $2 \mathrm{mM} \mathrm{L-glutamine,} \mathrm{penicillin}$ (100 U/mL), and streptomycin (100 $\mu \mathrm{g} / \mathrm{mL})$. Lipofectamine LTX (Life Technologies) reagent was used to transfect the cells according to the manufacturer's instructions. The cells were treated for 2 hours with the indicated concentration of compound the day after transfection before they were harvested in MKK-lysis buffer $(50 \mathrm{mM}$ Tris/ $\mathrm{HCl} \mathrm{pH}$ 7.5, $1 \mathrm{mM}$ EGTA, $1 \mathrm{mM}$ EDTA, 1\% $(\mathrm{w} / \mathrm{v})$ Triton-X 100, $1 \mathrm{mM}$ sodium orthovanadate, $50 \mathrm{mM}$ sodium fluoride, $5 \mathrm{mM}$ sodium pyrophosphate and $0.27 \mathrm{M}$ sucrose) and processed for immunoblotting.

\section{Immunoblotting}

For detection of ectopically expressed FLAG-TAU or EGFP-DYRK1A, the samples were analyzed by SDS-PAGE (4-12\% NUPAGE, Life Technologies), transferred to a nitrocellulose membrane (Li-Cor) and probed with a rabbit anti- Phospho-tau-T212 (1:1000) antibody or a mouse monoclonal anti-FLAG antibody. Detection and quantification were performed either 
directly using anti-GFP Dylight 800-conjugated antibody or IRDye 800CW-conjugated goat antirabbit IgG $(\mathrm{H} \& \mathrm{~L})(1: 10000)$ or IRDye 680LT-conjugated donkey anti-mouse IgG (H\&L) (1:10000) and the Odyssey Infrared Imaging System (Li-Cor Biosciences). Protein molecular mass was estimated using the MagicMark Western protein standard (Life technologies).

\section{Antibodies}

The polyclonal antibody against tau phosphorylated at threonine 212 (44-740G) was purchased from (Life Technologies). The monoclonal antibody against FLAG (F1804) was purchased from Sigma-Aldrich. The anti-GFP Dylight 800-conjugated antibody (600-145-215) was purchased from Rockland. The IRDye 800CW-conjugated goat anti-rabbit IgG (H\&L) and IRDye 680LTconjugated donkey anti-mouse IgG (H\&L) were purchased from Li-Cor Bioscience.

10. Generation of DYRK1A-NFAT-luc reporter cell line.

The pDEST-LTR-EGFP, a mammalian transfection vector for stable and doxycycline controlled inducible expression of N-terminal-EGFP tagged fusion constructs under the control of a truncated CMV promoter, was a kind gift from Dr. Trond Lamark UiT, Tromsø, Norway ${ }^{45}$. The cDNA encoding human DYRK1A was amplified from the IMAGE clone; IMAGE:100061742 with the following primers:

\section{5-CACCATGCATACAGGAGGAGAGACTTCAGC-3` and}

\section{5-TCACGAGCTAGCTACAGGACTCTG-3,}

cloned into the pENTR using the pENTR topo cloning kit (Thermo Fischer Scientific). The final pENTR-DYRK1a construct was verified by DNA sequencing. The DYRK1A was transferred from the pENTR-DYRK1A to the vector pDEST-LTR-EGFP to generate the retroviral 
expression vector pEXP-LRT-EGFP-DYRK1A using the Gateway LR reaction (Thermo Fischer Scientific).

Phoenix HEK cells were transfected with the pEXP-LRT-EGFP-DYRK1A plasmid using TransIT-LT1 transfection agent (Mirus Bio LLC) following the manufacturer's protocol. Fortyeight and seventy-two hours later the supernatant were collected and filtered through a $0.45 \mu \mathrm{m}$ filter. The supernatant was supplemented with $5 \mu \mathrm{g} / \mathrm{mL}$ proteome sulphate and used to transduce the NFAT / LUCPorter ${ }^{\mathrm{TM}}$ Stable Reporter HEK Cell Line (Novus Biologicals), which contains express a stable renilla reporter gene under control of a NFAT response element. Two day after the transduction the cell were reseeded in medium containing $5 \mu \mathrm{g} / \mathrm{mL}$ blasticidine and blasticidine resistant pools of cells were propagated and tested for expression of EGFP-DYRK1 fusion protein in absence and presence of $1 \mu \mathrm{g} / \mathrm{ml}$ doxycycline. (Supporting information)

\section{Kinome Profiling.}

Kinome profiling was performed using KinomeScan ScanMAX at compound concentration of $10 \mu \mathrm{M}$ or $1 \mu \mathrm{M}$. Data was reported in Supplementary data. Protocols are available from DiscoverX.

\section{ACKNOWLEDGEMENT}

We are grateful to Dr. D'Arcangelo ((Rutgers, USA) and Dr. Paudel (McGill, Canada) for providing expression vectors. The work was supported Northern Norway Regional Health Authority/Helse Nord RHF (A.C. and O.M.S.). We acknowledge the European Synchrotron 
Radiation Facility for provision of synchrotron radiation facilities. This research was supported by the Research Council of Norway through the grant (247732).

\begin{abstract}
ANCILLARY INFORMATION
Supporting information available: Complete table with all 23 inhibitors, molecular formula strings of the inhibitors, scaffolds of all 23 inhibitors. Crystallographic table of the nine crystal structures, omit maps, surface plots and a superimposition of all the nine inhibitors bound to the ATP pocket of DYRK1A. Table of the kinome scan. Additional tau phosphorylation assays. Overview of the cell based NFAT mediated luciferase reporter gene activity assay including the positive controls. NMR spectra of the compounds.

Accession Codes

PDB codes for DYRK1A complexes: compound AC12, 6EIF; compound AC15, 6EJ4; compound AC20, 6EIJ; compound AC22, 6EIL; compound AC23, 6EIP; compound AC24, 6EIQ; compound AC25, 6EIR; compound AC27, 6EIS; compound AC28, 6EIV.

Authors will release the atomic coordinates and experimental data upon article publication

\section{AUTHOR INFORMATION}

\section{Corresponding Author}

Corresponding author: *ulli.rothweiler@uit.no
\end{abstract}




\section{REFERENCES}

(1) Qiu, C.; Kivipelto, M.; von Strauss, E. Epidemiology of Alzheimer's disease: occurrence, determinants, and strategies toward intervention. Dialogues Clin Neurosci 2009, 11, 111-128.

(2) Hardy, J. Alzheimer's disease: the amyloid cascade hypothesis: an update and reappraisal. J Alzheimers Dis 2006, 9, 151-153.

(3) Hardy, J. A.; Higgins, G. A. Alzheimer's disease: the amyloid cascade hypothesis. Science 1992, 256, 184-185.

(4) Chetelat, G. Alzheimer disease: A beta-independent processes-rethinking preclinical AD. Nature Reviews Neurology 2013, 9, 123-124.

(5) Graham, W. V.; Bonito-Oliva, A.; Sakmar, T. P. Update on Alzheimer's disease therapy and prevention strategies. Annu Rev Med 2017, 68, 413-430.

(6) Lloret, A.; Fuchsberger, T.; Giraldo, E.; Vina, J. Molecular mechanisms linking amyloid beta toxicity and Tau hyperphosphorylation in Alzheimers disease. Free Radic Biol Med 2015, $83,186-191$.

(7) Ferrer, I.; Barrachina, M.; Puig, B.; de Lagran, M. M.; Marti, E.; Avila, J.; Dierssen, M. Constitutive Dyrk1A is abnormally expressed in Alzheimer disease, Down syndrome, Pick disease, and related transgenic models. Neurobiology of Disease 2005, 20, 392-400.

(8) Dierssen, M. Down syndrome: the brain in trisomic mode. Nature Reviews Neuroscience 2012, 13, 844-858.

(9) Ryoo, S. R.; Cho, H. J.; Lee, H. W.; Jeong, H. K.; Radnaabazar, C.; Kim, Y. S.; Kim, M. J.; Son, M. Y.; Seo, H.; Chung, S. H.; Song, W. J. Dual-specificity tyrosine(Y)-phosphorylation regulated kinase 1A-mediated phosphorylation of amyloid precursor protein: evidence for a 
functional link between Down syndrome and Alzheimer's disease. Journal of Neurochemistry 2008, 104, 1333-1344.

(10) Ryu, Y. S.; Park, S. Y.; Jung, M. S.; Yoon, S. H.; Kwen, M. Y.; Lee, S. Y.; Choi, S. H.; Radnaabazar, C.; Kim, M. K.; Kim, H.; Kim, K.; Song, W. J.; Chung, S. H. Dyrk1A-mediated phosphorylation of Presenilin 1: a functional link between Down syndrome and Alzheimer's disease. Journal of Neurochemistry 2010, 115, 574-584.

(11) Liu, F.; Liang, Z. H.; Wegiel, J.; Hwang, Y. W.; Iqbal, K.; Grundke-Iqbal, I.; Ramakrishna, N.; Gong, C. X. Overexpression of Dyrk1A contributes to neurofibrillary degeneration in Down syndrome. Faseb Journal 2008, 22, 3224-3233.

(12) Wegiel, J.; Gong, C. X.; Hwang, Y. W. The role of DYRK1A in neurodegenerative diseases. Febs Journal 2011, 278, 236-245.

(13) Belgardt, B. F.; Lammert, E. DYRK1A: A promising drug target for islet transplant-based diabetes therapies. Diabetes 2016, 65, 1496-1498.

(14) Dirice, E.; Walpita, D.; Vetere, A.; Meier, B. C.; Kahraman, S.; Hu, J.; Dancik, V.; Burns, S. M.; Gilbert, T. J.; Olson, D. E.; Clemons, P. A.; Kulkarni, R. N.; Wagner, B. K. Inhibition of DYRK1A stimulates human beta-cell proliferation. Diabetes 2016, 65, 1660-1671.

(15) Wang, P.; Alvarez-Perez, J. C.; Felsenfeld, D. P.; Liu, H. T.; Sivendran, S.; Bender, A.; Kumar, A.; Sanchez, R.; Scott, D. K.; Garcia-Ocana, A.; Stewart, A. F. A high-throughput chemical screen reveals that harmine-mediated inhibition of DYRK1A increases human pancreatic beta cell replication. Nature Medicine 2015, 21, 383-388.

(16) Cook, P. F.; Neville, M. E., Jr.; Vrana, K. E.; Hartl, F. T.; Roskoski, R., Jr. Adenosine cyclic 3',5'-monophosphate dependent protein kinase: kinetic mechanism for the bovine skeletal muscle catalytic subunit. Biochemistry 1982, 21, 5794-5799. 
(17) Alexeeva, M.; Aberg, E.; Engh, R. A.; Rothweiler, U. The structure of a dual-specificity tyrosine phosphorylation-regulated kinase 1A-PKC412 complex reveals disulfide-bridge formation with the anomalous catalytic loop HRD(HCD) cysteine. Acta Crystallogr D Biol Crystallogr 2015, 71, 1207-1215.

(18) Rothweiler, U.; Stensen, W.; Brandsdal, B. O.; Isaksson, J.; Leeson, F. A.; Engh, R. A.; Svendsen, J. S. Probing the ATP-binding pocket of protein kinase DYRK1A with benzothiazole fragment molecules. $J$ Med Chem 2016, 59, 9814-9824.

(19) Tahtouh, T.; Elkins, J. M.; Filippakopoulos, P.; Soundararajan, M.; Burgy, G.; Durieu, E.; Cochet, C.; Schmid, R. S.; Lo, D. C.; Dehommel, F.; Oberhozer, A. E.; Pearl, L. H.; Carreaux, F.; Bazureau, J. P.; Knapp, S.; Meijer, L. Selectivity, cocrystal structures, and neuroprotective properties of leucettines, a family of protein kinase inhibitors derived from the marine sponge alkaloid leucettamine B. J Med Chem 2012, 55, 9312-9330.

(20) Choi, H. G.; Zhang, J. M.; Weisberg, E.; Griffin, J. D.; Sim, T.; Gray, N. S. Development of 'DFG-out' inhibitors of gatekeeper mutant kinases. Bioorg Med Chem Lett 2012, 22, 5297 5302.

(21) Liu, Q. S.; Wang, J. H.; Kang, S. A.; Thoreen, C. C.; Hur, W.; Ahmed, T.; Sabatini, D. M.; Gray, N. S. Discovery of 9-(6-aminopyridin-3-yl)-1-(3-(trifluoromethyl)phenyl)benzo[h][1,6]naphthyridin-2(1H)-one (Torin2) as a potent, selective, and orally available mammalian target of raparnycin (mTOR) inhibitor for treatment of cancer. J Med Chem 2011, 54, 1473-1480.

(22) Nguyen, T. L.; Fruit, C.; Herault, Y.; Meijer, L.; Besson, T. Dual-specificity tyrosine phosphorylation-regulated kinase 1A (DYRK1A) inhibitors: a survey of recent patent literature. Expert Opin Ther Pat 2017, 11, 1-17. 
(23) Ogawa, Y.; Nonaka, Y.; Goto, T.; Ohnishi, E.; Hiramatsu, T.; Kii, I.; Yoshida, M.; Ikura, T.; Onogi, H.; Shibuya, H.; Hosoya, T.; Ito, N.; Hagiwara, M. Development of a novel selective inhibitor of the Down syndrome-related kinase Dyrk1 A. Nat Commun 2010, 1, 86.

(24) Masaki, S.; Kii, I.; Sumida, Y.; Kato-Sumida, T.; Ogawa, Y.; Ito, N.; Nakamura, M.; Sonamoto, R.; Kataoka, N.; Hosoya, T.; Hagiwara, M. Design and synthesis of a potent inhibitor of class 1 DYRK kinases as a suppressor of adipogenesis. Bioorgan Med Chem 2015, 23, 44344441.

(25) Ruben, K.; Wurzlbauer, A.; Walte, A.; Sippl, W.; Bracher, F.; Becker, W. Selectivity profiling and biological activity of novel beta-carbolines as potent and selective DYRK1 kinase inhibitors. PLoS One 2015, 10.

(26) De la Torre, R.; De Sola, S.; Pons, M.; Duchon, A.; de Lagran, M. M.; Farre, M.; Fito, M.; Benejam, B.; Langohr, K.; Rodriguez, J.; Pujadas, M.; Bizot, J. C.; Cuenca, A.; Janel, N.; Catuara, S.; Covas, M. I.; Blehaut, H.; Herault, Y.; Delabar, J. M.; Dierssen, M. Epigallocatechin-3-gallate, a DYRK1A inhibitor, rescues cognitive deficits in Down syndrome mouse models and in humans. Mol Nutr Food Res 2014, 58, 278-288.

(27) Coutadeur, S.; Benyamine, H.; Delalonde, L.; de Oliveira, C.; Leblond, B.; Foucourt, A.; Besson, T.; Casagrande, A. S.; Taverne, T.; Girard, A.; Pando, M. P.; Desire, L. A novel DYRK1A (dual specificity tyrosine phosphorylation-regulated kinase 1A) inhibitor for the treatment of Alzheimer's disease: effect on Tau and amyloid pathologies in vitro. J Neurochem 2015, 133, 440-451.

(28) Chaikuad, A.; Diharce, J.; Schroder, M.; Foucourt, A.; Leblond, B.; Casagrande, A. S.; Desire, L.; Bonnet, P.; Knapp, S.; Besson, T. An unusual binding model of the methyl 9anilinothiazolo[5,4-f] quinazoline-2-carbimidates (EHT 1610 and EHT 5372) confers high 
selectivity for dual-specificity tyrosine phosphorylation-regulated kinases. J Med Chem 2016, 59, 10315-10321.

(29) Naert, G.; Ferre, V.; Meunier, J.; Keller, E.; Malmstrom, S.; Givalois, L.; Carreaux, F.; Bazureau, J. P.; Maurice, T. Leucettine L41, a DYRK1A-preferential DYRKs/CLKs inhibitor, prevents memory impairments and neurotoxicity induced by oligomeric A beta(25-35) peptide administration in mice. Eur Neuropsychopharm 2015, 25, 2170-2182.

(30) Rothweiler, U.; Eriksson, J.; Stensen, W.; Leeson, F.; Engh, R. A.; Svendsen, J. S.

Luciferin and derivatives as a DYRK selective scaffold for the design of protein kinase inhibitors. Eur J Med Chem 2015, 94, 140-148.

(31) Kii, I.; Sumida, Y.; Goto, T.; Sonamoto, R.; Okuno, Y.; Yoshida, S.; Kato-Sumida, T.; Koike, Y.; Abe, M.; Nonaka, Y.; Ikura, T.; Ito, N.; Shibuya, H.; Hosoya, T.; Hagiwara, M. Selective inhibition of the kinase DYRK1A by targeting its folding process. Nat Commun 2016, $7,11391$.

(32) Hong, S.; Kim, J.; Seo, J. H.; Jung, K. H.; Hong, S. S.; Hong, S. Design, synthesis, and evaluation of 3,5-disubstituted 7-azaindoles as Trk inhibitors with anticancer and antiangiogenic activities. J Med Chem 2012, 55, 5337-5349.

(33) Choi, H. G., Sim, T., Gray, N., Zhou, W., Chang, J. W, Zhang, J., Weisberg, E. Fused Heterocyclic Compounds and their Uses, PCT Int. Appl., WO 2010144909 A1 20101216. 2010. (34) Miduturu, C. V.; Deng, X.; Kwiatkowski, N.; Yang, W.; Brault, L.; Filippakopoulos, P.; Chung, E.; Yang, Q.; Schwaller, J.; Knapp, S.; King, R. W.; Lee, J. D.; Herrgard, S.; Zarrinkar, P.; Gray, N. S. High-throughput kinase profiling: a more efficient approach toward the discovery of new kinase inhibitors. Chem Biol 2011, 18, 868-879.

(35) Liu, Q.; Wang, J.; Kang, S. A.; Thoreen, C. C.; Hur, W.; Ahmed, T.; Sabatini, D. M.; Gray, N. S. Discovery of 9-(6-aminopyridin-3-yl)-1-(3- 
(trifluoromethyl)phenyl)benzo[h][1,6]naphthyridin-2( $1 \mathrm{H})$-one (Torin2) as a potent, selective, and orally available mammalian target of rapamycin (mTOR) inhibitor for treatment of cancer. $J$ Med Chem 2011, 54, 1473-1480.

(36) Lee, S.; Shang, Y.; Redmond, S. A.; Urisman, A.; Tang, A. A.; Li, K. H.; Burlingame, A. L.; Pak, R. A.; Jovicic, A.; Gitler, A. D.; Wang, J.; Gray, N. S.; Seeley, W. W.; Siddique, T.; Bigio, E. H.; Lee, V. M.; Trojanowski, J. Q.; Chan, J. R.; Huang, E. J. Activation of HIPK2 promotes ER stress-mediated neurodegeneration in amyotrophic lateral sclerosis. Neuron 2016, 91, 41-55.

(37) Bruce, I., Budd, E., Edwards, L., Howsham, C. Pyridines and Pyrazines as Inhibitors of Pi3k, PCT Int. Appl., WO 2009115517 A2 20090924. 2009.

(38) Krug, M.; Weiss, M. S.; Heinemann, U.; Mueller, U. XDSAPP: a graphical user interface for the convenient processing of diffraction data using XDS. J Appl Crystallogr 2012, 45, 568572.

(39) Adams, P. D.; Afonine, P. V.; Bunkoczi, G.; Chen, V. B.; Davis, I. W.; Echols, N.; Headd, J. J.; Hung, L. W.; Kapral, G. J.; Grosse-Kunstleve, R. W.; McCoy, A. J.; Moriarty, N. W.; Oeffner, R.; Read, R. J.; Richardson, D. C.; Richardson, J. S.; Terwilliger, T. C.; Zwart, P. H. PHENIX: a comprehensive Python-based system for macromolecular structure solution. Acta Crystallogr D Biol Crystallogr 2010, 66, 213-221.

(40) Winn, M. D.; Ballard, C. C.; Cowtan, K. D.; Dodson, E. J.; Emsley, P.; Evans, P. R.; Keegan, R. M.; Krissinel, E. B.; Leslie, A. G.; McCoy, A.; McNicholas, S. J.; Murshudov, G. N.; Pannu, N. S.; Potterton, E. A.; Powell, H. R.; Read, R. J.; Vagin, A.; Wilson, K. S. Overview of the CCP4 suite and current developments. Acta Crystallogr D Biol Crystallogr 2011, 67, 235242. 
(41) Murshudov, G. N.; Skubak, P.; Lebedev, A. A.; Pannu, N. S.; Steiner, R. A.; Nicholls, R. A.; Winn, M. D.; Long, F.; Vagin, A. A. REFMAC5 for the refinement of macromolecular crystal structures. Acta Crystallogr D Biol Crystallogr 2011, 67, 355-367.

(42) Emsley, P.; Lohkamp, B.; Scott, W. G.; Cowtan, K. Features and development of Coot. Acta Crystallogr D Biol Crystallogr 2010, 66, 486-501.

(43) Yabut, O.; Domogauer, J.; D'Arcangelo, G. Dyrk1A overexpression inhibits proliferation and induces premature neuronal differentiation of neural progenitor cells. Journal of Neuroscience 2010, 30, 4004-4014.

(44) Li, T.; Paudel, H. K. Glycogen synthase kinase 3 beta phosphorylates Alzheimer's disease-specific Ser(396) of microtubule-associated protein tau by a sequential mechanism. Biochemistry 2006, 45, 3125-3133.

(45) Skytte Rasmussen, M.; Mouilleron, S.; Kumar Shrestha, B.; Wirth, M.; Lee, R.; Bowitz Larsen, K.; Abudu Princely, Y.; O'Reilly, N.; Sjottem, E.; Tooze, S. A.; Lamark, T.; Johansen, T. ATG4B contains a C-terminal LIR motif important for binding and efficient cleavage of mammalian orthologs of yeast Atg8. Autophagy 2017, 13, 834-853. 


\section{Table of Contents graphic}

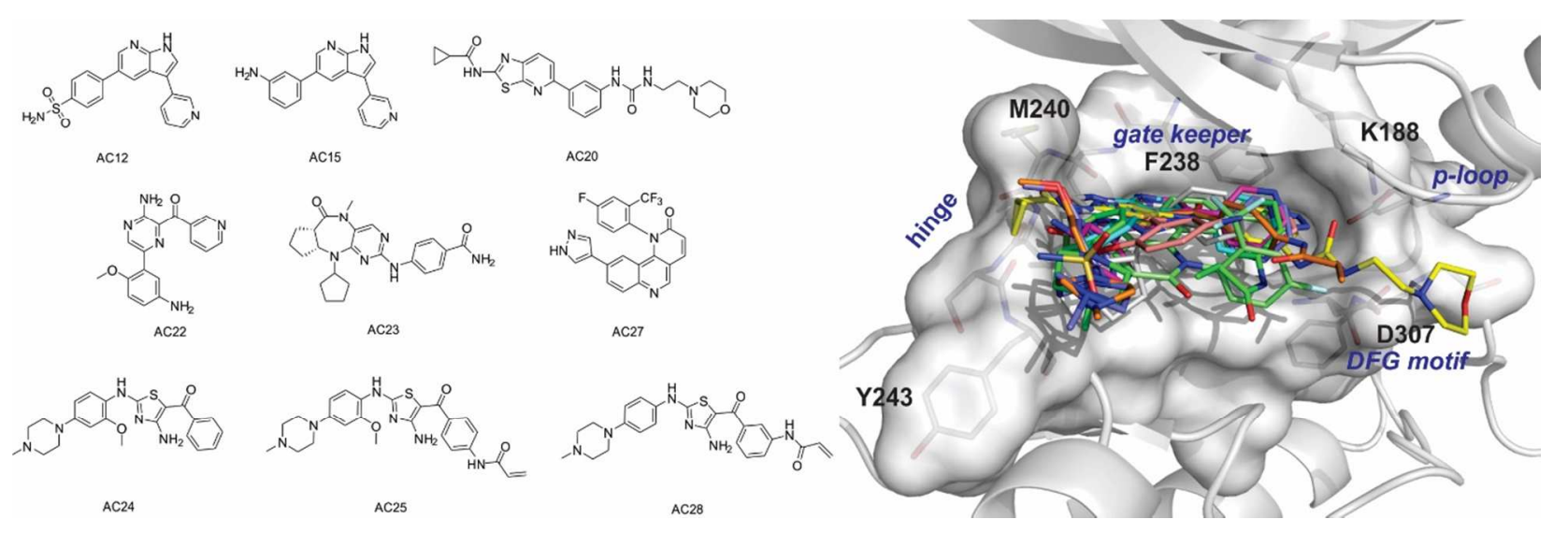

